\title{
3-D dynamic rupture simulations of the 2016 Kumamoto, Japan, earthquake
}

\author{
Yumi Urata ${ }^{1 *} \mathbb{0}$, Keisuke Yoshida $^{2}$, Eiichi Fukuyama ${ }^{1}$ and Hisahiko Kubo ${ }^{1}$
}

\begin{abstract}
Using 3-D dynamic rupture simulations, we investigated the $2016 \mathrm{M}_{\mathrm{w}} 7.1$ Kumamoto, Japan, earthquake to elucidate why and how the rupture of the main shock propagated successfully, assuming a complicated fault geometry estimated on the basis of the distributions of the aftershocks. The $M_{w} 7.1$ main shock occurred along the Futagawa and Hinagu faults. Within $28 \mathrm{~h}$ before the main shock, three M6-class foreshocks occurred. Their hypocenters were located along the Hinagu and Futagawa faults, and their focal mechanisms were similar to that of the main shock. Therefore, an extensive stress shadow should have been generated on the fault plane of the main shock. First, we estimated the geometry of the fault planes of the three foreshocks as well as that of the main shock based on the temporal evolution of the relocated aftershock hypocenters. We then evaluated the static stress changes on the main shock fault plane that were due to the occurrence of the three foreshocks, assuming elliptical cracks with constant stress drops on the estimated fault planes. The obtained static stress change distribution indicated that Coulomb failure stress change ( $\triangle C F S$ ) was positive just below the hypocenter of the main shock, while the $\triangle C F S$ in the shallow region above the hypocenter was negative. Therefore, these foreshocks could encourage the initiation of the main shock rupture and could hinder the propagation of the rupture toward the shallow region. Finally, we conducted 3-D dynamic rupture simulations of the main shock using the initial stress distribution, which was the sum of the static stress changes caused by these foreshocks and the regional stress field. Assuming a slip-weakening law with uniform friction parameters, we computed 3-D dynamic rupture by varying the friction parameters and the values of the principal stresses. We obtained feasible parameter ranges that could reproduce the characteristic features of the main shock rupture revealed by seismic waveform analyses. We also observed that the free surface encouraged the slip evolution of the main shock.
\end{abstract}

Keywords: The 2016 Kumamoto earthquake, Numerical simulation, Dynamic rupture propagation, Foreshocks

\section{Introduction}

Earthquakes cause dynamic and static stress changes in the surrounding area. Both the dynamic and static stress changes can then trigger earthquakes, and a stress shadow appears where the Coulomb failure stress change $(\triangle C F S)$ is negative and subsequent seismicity tends to cease (e.g., King et al. 1994; Stein et al. 1997; Kilb et al. 2000; Toda et al. 2012).

On April 16, 2016, at 01:25 (JST, UT +9 h), the $M_{w} 7.1$ main shock of the 2016 Kumamoto, Japan, earthquake sequence occurred along the Hinagu and Futagawa faults

\footnotetext{
*Correspondence: urata@bosai.go.jp

${ }^{1}$ National Research Institute for Earth Science and Disaster Resilience

(NIED), 3-1 Tennodai, Tsukuba, Ibaraki 305-0006, Japan

Full list of author information is available at the end of the article
}

(Fig. 1). The largest slip was shown to occur at a portion of the Futagawa fault shallower than $12 \mathrm{~km}$ by seismic waveform inversion analyses (Asano and Iwata 2016; Kubo et al. 2016; Uchide et al. 2016; Yagi et al. 2016; Kobayashi et al. 2017; Hao et al. 2017) as well as in the geodetic data (Himematsu and Furuya 2016). These studies reported the maximum slip amount was $4-6 \mathrm{~m}$. The seismic waveform inversion results suggested that the slip of the main shock occurred on the Hinagu fault first and propagated to the Futagawa fault at a depth of $10-15 \mathrm{~km}$ at 2-4 s (Asano and Iwata 2016; Kubo et al. 2016; Uchide et al. 2016; Hao et al. 2017). Then, the large slip occurred on the Futagawa fault at a depth of 4-12 km for 6-10 s, and on the shallower region of the Futagawa fault later than 8 s (Asano and Iwata 2016; Kubo et al. 2016; Uchide 


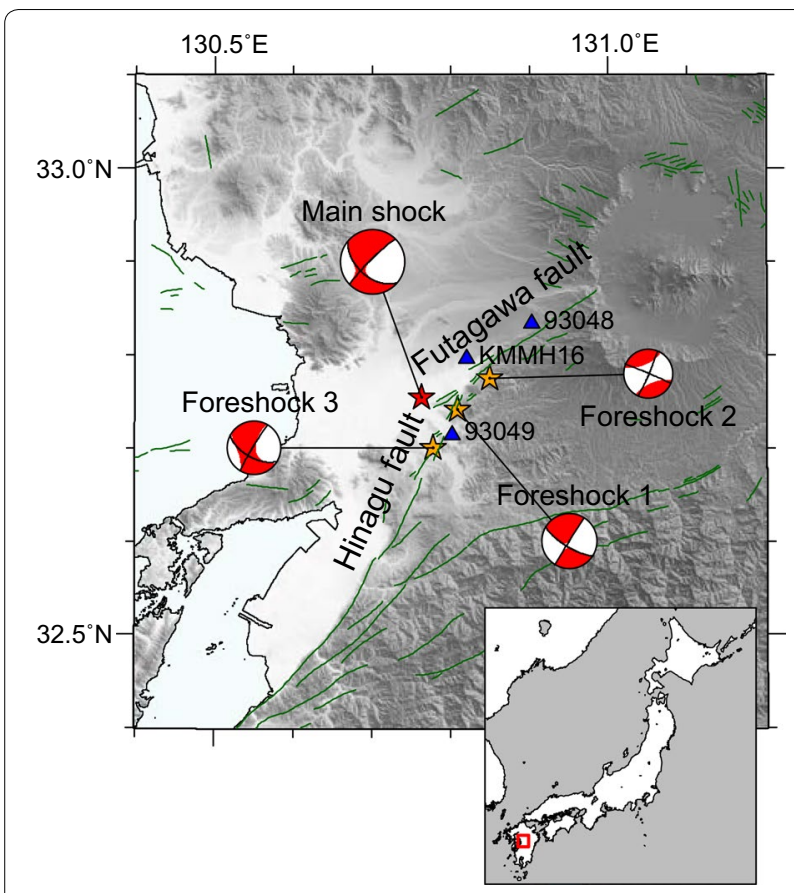

Fig. 1 Map of the studied area, indicated by red rectangle in the lower-right inset. Orange and red stars denote the locations of the epicenters of the three foreshocks and the main shock, respectively. MT solutions of the foreshocks and the main shock (National Research Institute for Earth Science and Disaster Resilience (NIED). http://www. fnet.bosai.go.jp/event/joho.php?LANG=en. Accessed April 21, 2017) are shown. Green lines represent surface traces of active faults as determined by RGAFJ (1991)

et al. 2016; Hao et al. 2017). Yagi et al. (2016) and Hao et al. (2017) reported from the waveform inversion that the observed moment rate function was $6.3 \times 10^{18} \mathrm{Nm} / \mathrm{s}$ at maximum at 8-9 s and became zero at $15-18 \mathrm{~s}$. Field investigations showed that the main shock produced surface ruptures along the Hinagu and Futagawa fault zones, and the maximum slip (larger than $2 \mathrm{~m}$ ) was observed in the Futagawa segment (Lin et al. 2016; Shirahama et al. 2016).

Within $28 \mathrm{~h}$ before the main shock, three M6-class foreshocks had occurred: an $M_{w} 6.1$ foreshock on April 14 at 21:26 (JST, foreshock 1), an $\mathrm{M}_{\mathrm{w}} 5.4$ foreshock on April 14 at 22:07 (JST, foreshock 2), and an $M_{w} 6.0$ foreshock on April 15 at 00:03 (JST, foreshock 3). Their hypocenters were located along the Hinagu and Futagawa faults, and the moment tensor (MT) solutions of foreshocks 1 and 3 were similar to those of the main shock (Fig. 1). Therefore, an extensive stress shadow should have been generated on the main shock fault plane.

The purpose of this study is to investigate why and how the main shock rupture propagated successfully under such complicated stress conditions. We first estimate the fault planes of the three foreshocks and the main shock using the distributions of the aftershocks ("Estimation of fault planes" section). Then, taking into account the static stress changes induced by the three foreshocks ("Static stress changes by foreshocks" section), we conduct multiple 3-D dynamic rupture simulations of the main shock ("3-D dynamic rupture simulations of the main shock" section). In the simulations, we examine various values of the magnitudes of the maximum and minimum principal stresses, slip-weakening distance $D_{\mathrm{c}}$, and the ratio of the yield stress and the stress drop on the Hinagu fault $S_{\mathrm{H}}$, as a set of independent parameters, assuming a slipweakening law. The $S_{\mathrm{H}}$ value controls the static coefficient of friction $\mu_{\mathrm{s}}$ (i.e., the yield stress) because the dynamic coefficient of friction $\mu_{\mathrm{d}}$ (i.e., stress drop) can be estimated from the observed seismic moment. Finally, we discuss the conditions to reproduce the features of the main shock rupture stated above ("Results" and "Discussion" sections).

\section{Estimation of fault planes}

We first estimate the locations of the fault planes of the three M6-class foreshocks and the main shock. Since the relative hypocenter locations of aftershocks generally have much higher spatial resolution at depth than most other seismological and geodetic estimates, we utilized the aftershock distributions of those earthquakes obtained by Yoshida et al. (2016) based on the doubledifference hypocenter relocation technique (Waldhauser and Ellsworth 2000).

The distribution of aftershock hypocenters estimated by Yoshida et al. (2016) is shown in Fig. 2 for the period from April 14, 2016, to June 11, 2016. Several alignments of the aftershock hypocenters corresponding to the fault planes of the main shock can be recognized. However, some ambiguities arose when determining a distinct fault plane because the aftershocks seemed to have occurred not only on the fault but also off of the fault. We then investigated the time evolution of the aftershock hypocenters in detail for the period between foreshock 1 and the main shock, as shown in Fig. 3.

After each foreshock, the alignments of the aftershock hypocenters corresponding to their fault planes appeared. To estimate the detailed locations of the fault planes of the three M6-class foreshocks and the main shock, we started by assuming the initial fault planes whose centroids were located at the hypocenter of each main shock. The orientations of the fault planes were determined from the nodal planes of their F-net focal mechanisms determined by the National Research Institute for Earth Science and Disaster Resilience (NIED) (Fukuyama et al. 2000), with reference to the aftershock distributions to determine the preferable plane (Fig. 3). The lengths and widths of the fault planes were derived 


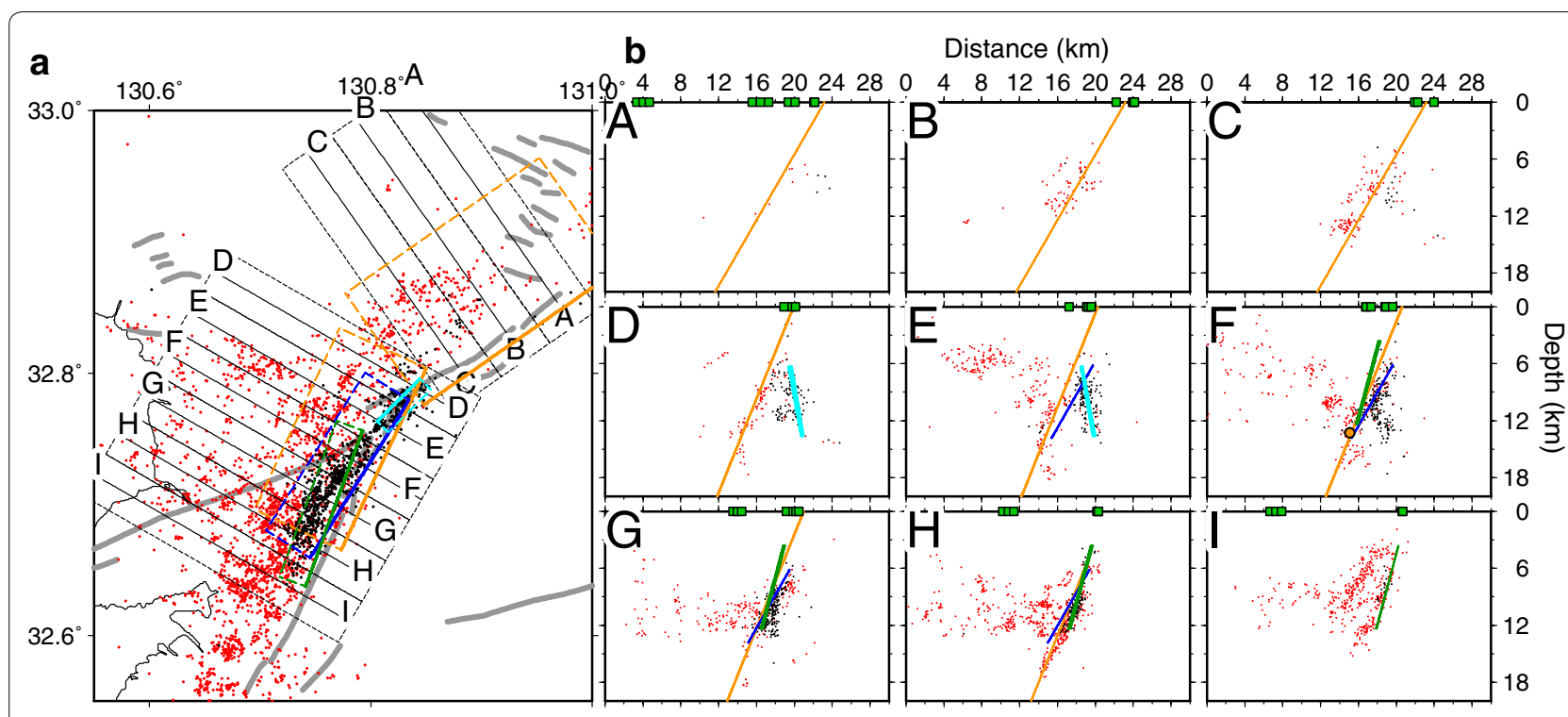

Fig. 2 Spatial distribution of the estimated fault planes. The estimated fault planes of foreshocks 1, 2, and 3, and the main shock are indicated by blue, light blue, green and orange lines, respectively, on $\mathbf{a}$ the map view and $\mathbf{b}$ the cross-sectional views. Circles show the hypocenters for the period from April 14, 2016 to June 11, 2016. Black and red denote the hypocenters before and after the main shock, respectively

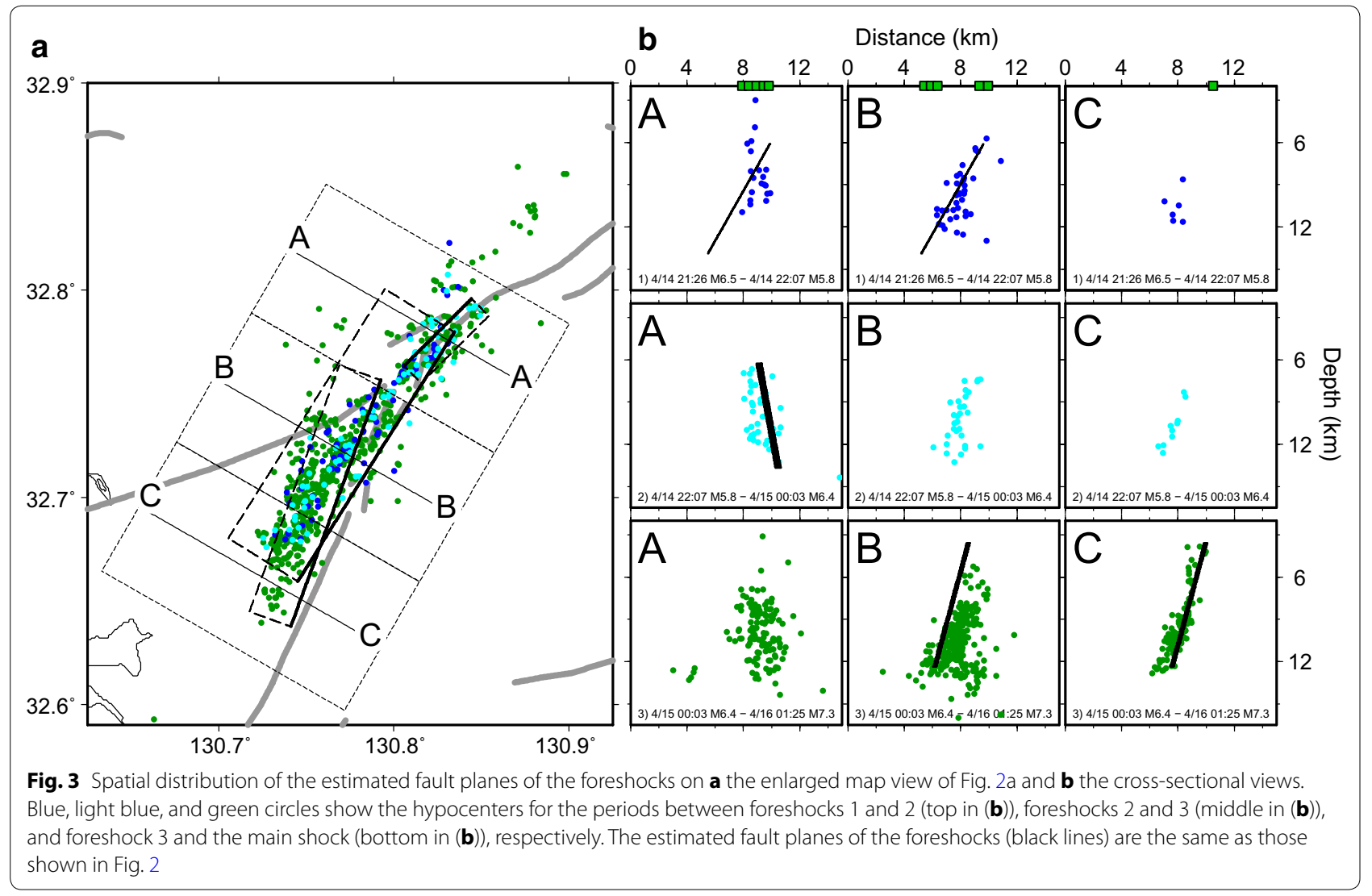

from the empirical scaling relations for magnitude, slip amount, fault length and fault width (Utsu 2001). We then adjusted the location and orientation of the initial fault models to obtain better alignment with the hypocenter distribution of their aftershocks in Figs. 2 and 3. We manually fit the data with our own eyes to estimate 
more robust and reliable fault geometry than that by fitting them with regression analysis because of the existence of events occurring off the main shock faults (Fig. 3). Furthermore, we constrained the shallow portions of the fault planes by referring to the observed surface ruptures of the main shock. This is because it was difficult to estimate the shallow portion (depths of less than a few kilometers) of the fault plane from the aftershock distribution due to very few aftershocks at the shallow depth as well as the uncertainties in the focal depth of very shallow events.

The obtained geometries of the fault planes of the three M6-class foreshocks and the main shock are shown in Figs. 2 and 3 and Table 1. We obtained two distinct fault segments of the main shock corresponding to ruptures along the Hinagu and Futagawa fault segments. The obtained fault planes of foreshocks 1 and 3 crossed the obtained Hinagu fault segment. In the following sections, we consider a non-planar fault surface (orange lines in Fig. 4a) connecting the two estimated fault planes, which is used for dynamic rupture simulations.

\section{Static stress changes by foreshocks}

In this section, we evaluate the static stress changes on the estimated fault planes of the main shock due to the occurrence of the three foreshocks. The integral of the slip (i.e., average of slip) of each foreshock was determined from the observed seismic moment shown in Table 1. The shape of the slip distribution was assumed, according to Eshelby (1957)'s solution for an elliptical crack with a constant stress drop. This slip model can avoid stress singularities around the edge of the fault with the uniform slip distribution. We used the analytical solution because the slip distribution was estimated only for the largest foreshock by waveform inversions initially (Kubo et al. 2016; Asano and Iwata 2016), although most recently the slip distribution of foreshock 3 was estimated by Kobayashi et al. (2017). The details of the procedure are described in "Appendix 1" section. Figure $4 \mathrm{~b}$ shows the obtained slip distributions. We assumed a Poisson's ratio of 0.25 and a rigidity of $31.46 \mathrm{GPa}$. These values were calculated from the $\mathrm{P}$ - and $\mathrm{S}$-wave velocities by Saiga et al. (2010) and the rock density shown in Table 2. The static stress changes on the fault plane of the main shock were calculated using Okada (1992)'s solution. In this calculation, the slip distribution of the foreshocks was discretized into $100 \mathrm{~m}^{2}$. Figure 5a shows $\Delta \mathrm{CFS}\left(=\Delta \tau^{\mathrm{f}}-\mu_{\mathrm{s}} \Delta \sigma_{\mathrm{n}}^{\mathrm{f}}\right)$, where $\Delta \tau^{\mathrm{f}}$ and $\Delta \sigma_{\mathrm{n}}^{\mathrm{f}}($ compression is taken as positive) are the shear and normal components of the static stress changes due to the occurrence of the three foreshocks and $\mu_{\mathrm{s}}$ is the static coefficient of friction. In the calculation of $\triangle \mathrm{CFS}$, the non-planar fault was assumed to be a pure strike-slip fault, and $\mu_{\mathrm{s}}$ was assumed as 0.349 , which will be used in some of dynamic rupture simulations. The obtained $\triangle$ CFS distribution showed that the $\triangle$ CFS was positive just below the hypocenter of the main shock obtained by Yoshida et al. (2016), while the $\triangle$ CFS was negative in the shallow region above the hypocenter. The large negative $\triangle \mathrm{CFS}$ was produced by foreshocks 1 and 3 . The positive $\Delta$ CFS values just below the hypocenter were produced dominantly by foreshock 1 . Foreshock 2 changed the stresses in the Hinagu fault, the junction, and the shallow southern part of the Futagawa fault, but the changes were two orders of magnitude smaller than those produced by foreshocks 1 and 3 . Therefore, foreshock 1 could have encouraged the initiation of the main shock rupture and foreshocks 1 and 3 could have hindered the rupture propagating toward the shallow region.

\section{3-D dynamic rupture simulations of the main shock} We conducted multiple 3-D dynamic rupture simulations of the main shock under the initial stresses, which were determined as the sum of the static stress changes

Table 1 Estimated fault parameters and seismic moment of the foreshocks and the main shock

\begin{tabular}{|c|c|c|c|c|c|c|c|c|c|}
\hline \multirow[t]{2}{*}{ Event } & \multicolumn{3}{|c|}{ Center position of fault } & \multirow[t]{2}{*}{ Length (km) } & \multirow[t]{2}{*}{ Width (km) } & \multirow[t]{2}{*}{ Strike $\left({ }^{\circ}\right)$} & \multirow[t]{2}{*}{$\operatorname{Dip}\left({ }^{\circ}\right)$} & \multirow[t]{2}{*}{ Rake $\left(^{\circ}\right)$} & \multirow{2}{*}{$\begin{array}{l}\text { Seismic moment } \\
(\mathrm{Nm})^{\mathrm{a}}\end{array}$} \\
\hline & Longitude $\left({ }^{\circ} \mathrm{E}\right)$ & Latitude $\left({ }^{\circ} \mathrm{N}\right)$ & Depth $(\mathbf{k m})$ & & & & & & \\
\hline Foreshock 1 & 130.7700 & 32.7300 & 10.0 & 15.8 & 8.9 & 212 & 60.5 & $-164^{\mathrm{a}}$ & $1.74 \times 10^{18}$ \\
\hline Foreshock 2 & 130.8300 & 32.7755 & 9.97 & 5.1 & 7.5 & 45 & 80.0 & $-178^{a}$ & $1.27 \times 10^{1 /}$ \\
\hline Foreshock 3 & 130.7550 & 32.7007 & 7.97 & 14.1 & 9.1 & 200 & 75.0 & $-152^{\mathrm{a}}$ & $1.06 \times 10^{18}$ \\
\hline $\begin{array}{l}\text { Main shock (Hinagu } \\
\text { fault) }\end{array}$ & 130.7725 & 32.7500 & 10.0 & 17.0 & 21.58 & 205 & 68.0 & $(-165)^{b}$ & $4.42 \times 10^{19}$ \\
\hline $\begin{array}{l}\text { Main shock (Futa- } \\
\text { gawa fault) }\end{array}$ & 130.9000 & 32.8700 & 10.0 & 20.0 & 23.1 & 235 & 60.0 & $(-123)^{b}$ & \\
\hline
\end{tabular}

\footnotetext{
a The values were derived from the F-net moment tensor solutions
}

b These values were calculated from the regional stress field. The slip direction of the main shock in dynamic rupture simulations is the same as the shear stress direction determined from the regional stress field, the static stress change due to the foreshocks, and the dynamic stress change during the rupture propagation 

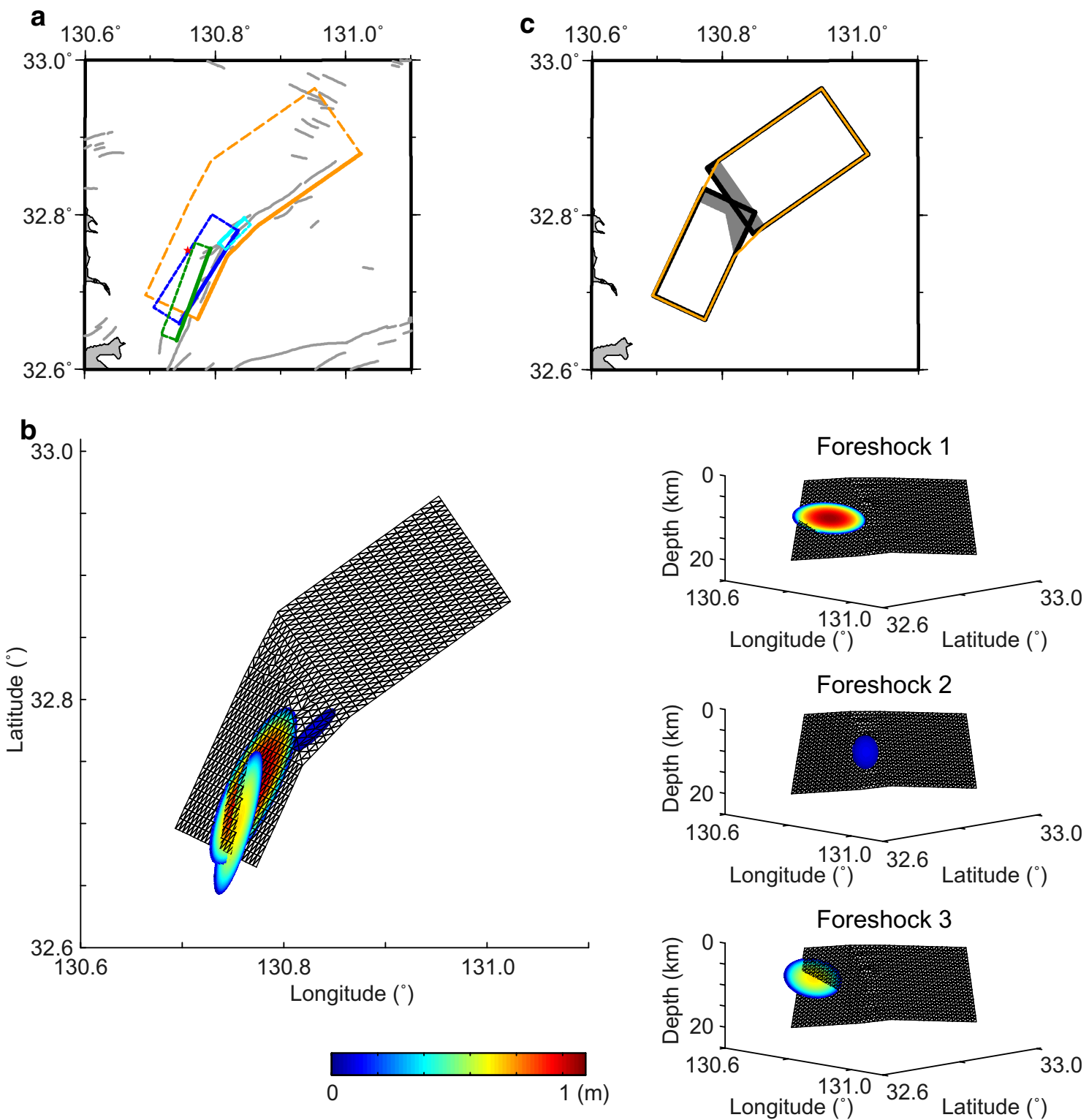

Fig. 4 a Estimated fault planes of the foreshocks (blue, light blue, and green lines) and a non-planar fault model of the main shock used in dynamic rupture simulations (orange lines). The fault planes of the foreshocks are the same as those shown in Fig. 2, and the main shock fault surface was built by connecting the estimated fault planes of the main shock shown in Fig. 2. Red star denote the epicenter of the main shock. b Assumed slip distributions of the three foreshocks in the map view (left panel) and in the view from the southeast (right panels). Black lines show triangular elements of a non-planar fault used in dynamic rupture simulations of the main shock. $\mathbf{c}$ How to generate the single fault interface (orange lines) from the two estimated fault planes of the main shock (black rectangles). The orange lines and the black rectangles are the same as the orange lines in (a) and the orange rectangles in Fig. 2a, respectively. The elements indicated by gray were removed at the connecting edges of the two fault planes, and fault elements were filled between both edges forming a non-planar fault segment

induced by the three foreshocks estimated in the previous section and the regional stress field based on the focal mechanism data by Yoshida et al. (2016) (Fig. 5b, c).

For spontaneous rupture simulations, we used the 3-D boundary integral equation method (BIEM) with triangular elements by Hok and Fukuyama (2011) and a slip-weakening law with the Coulomb failure criteria (Ida 1972):

$\tau= \begin{cases}\mu_{\mathrm{s}} \sigma_{\mathrm{n}}-\left(\mu_{\mathrm{s}} \sigma_{\mathrm{n}}-\mu_{\mathrm{d}} \sigma_{\mathrm{n}}\right) \Delta u / D_{\mathrm{c}} & 0 \leq \Delta u<D_{\mathrm{c}} \\ \mu_{\mathrm{d}} \sigma_{\mathrm{n}} & \Delta u \geq D_{\mathrm{c}}\end{cases}$ 
Table 2 Parameters used in dynamic rupture simulations

\begin{tabular}{ll}
\hline Property & Value \\
\hline Strike of the maximum principal stress, $\sigma_{1}$ & $\mathrm{~N} 68.83^{\circ} \mathrm{E}^{\mathrm{a}}$ \\
Dip of the maximum principal stress, $\sigma_{1}$ & $3.69^{\circ \mathrm{a}}$ \\
Strike of the intermediate principal stress, $\sigma_{2}$ & $\mathrm{~N} 232.98^{\circ} \mathrm{E}^{\mathrm{a}}$ \\
Dip of the intermediate principal stress, $\sigma_{2}$ & $86.17^{\circ \mathrm{a}}$ \\
Strike of the minimum principal stress, $\sigma_{3}$ & $\mathrm{~N} 338.77^{\circ} \mathrm{E}^{\mathrm{a}}$ \\
Dip of the minimum principal stress, $\sigma_{3}$ & $1.04^{\circ \mathrm{a}}$ \\
Stress ratio, $R=\frac{\sigma_{1}-\sigma_{2}}{\sigma_{1}-\sigma_{3}}$ & $0.19^{\mathrm{a}}$ \\
P-wave velocity & $5912.5 \mathrm{~m} / \mathrm{s}^{\mathrm{b}}$ \\
S-wave velocity & $3413.6 \mathrm{~m} / \mathrm{s}^{\mathrm{b}}$ \\
Rock density & $2700 \mathrm{~kg} / \mathrm{m}^{3}$ \\
\hline
\end{tabular}

a The regional stress field was estimated by Yoshida et al. (2016)

b Averages of the velocities at depths from 0 to $20 \mathrm{~km}$ obtained by Saiga et al. (2010)

where $\tau$ is the shear stress, $\sigma_{\mathrm{n}}$ is the normal stress, $\mu_{\mathrm{s}}$ and $\mu_{\mathrm{d}}$ are the static and dynamic coefficients of friction, respectively, $D_{\mathrm{c}}$ is the slip-weakening distance, and $\Delta u$ is the slip. For elements on the border of the fault, $D_{\mathrm{c}}$ is set to be infinite, that is, $\tau=\mu_{\mathrm{s}} \sigma_{\mathrm{n}}$, for the stability of the calculations. Except for these elements, the $D_{\mathrm{c}}$ values are assumed to be uniform, as are the friction coefficients. The slip direction is the same as the shear stress direction. The initial shear and normal stresses, $\tau^{0}$ and $\sigma_{\mathrm{n}}^{0}$, are $\tau^{\mathrm{r}}+\Delta \tau^{\mathrm{f}}$ and $\sigma_{\mathrm{n}}^{\mathrm{r}}+\Delta \sigma_{\mathrm{n}}^{\mathrm{f}}$, respectively, where $\tau^{\mathrm{r}}$ and $\sigma_{\mathrm{n}}^{\mathrm{r}}$ are the regional shear and normal stresses, respectively. Note that $\tau^{\mathrm{r}}, \sigma_{\mathrm{n}}^{\mathrm{r}}, \Delta \tau^{\mathrm{f}}, \Delta \sigma_{\mathrm{n}}^{\mathrm{f}}$, and the slip direction are functions of the location on the fault.

In some cases, a rupture initiated and propagated spontaneously from regions of high $\triangle \mathrm{CFS}$ on the Hinagu fault (Fig. 5a). For the rest, the rupture was forced to be initiated by artificially increasing shear stress to $\mu_{\mathrm{s}} \sigma_{\mathrm{n}}^{0}+1 \mathrm{kPa}$ in a small elliptical patch at the hypocenter on the Hinagu fault, and it then propagated spontaneously. The direction of the long axis of the ellipse was the same as the slip direction in the element nearest the hypocenter of the main shock. The aspect ratio of the ellipse was $4 / 3$, which is equal to the ratio of critical lengths $L_{\mathrm{c}}$ (a halfcrack length necessary for dynamic rupture propagation; Andrews 1976a, b) for modes II and III in a Poissonian medium. The artificial nucleation area was set to the minimum required to initiate a rupture. We assumed that the nucleation area should be $<1 / 3$ of the Hinagu fault area, i.e., we excluded the cases where the nucleation area was equal to or larger than $1 / 3$ of it.

We built a single fault interface composed of the 1664 triangular elements (orange line in Fig. 4a) from the two estimated fault planes of the main shock (Table 1 ) by connecting them with a non-planar fault. Figure 4c shows how to generate the single fault interface. The fault elements shown by gray in Fig. 4c were removed at the connecting edges of the two fault planes, and fault elements were filled between both edges forming a non-planar fault segment. Then, the single fault interface was generated. We refer the non-planar segment as a junction. The strike of the upper edge of the fault surface was consistent with the surface traces of active faults. Each triangular element except for the junction had a $0.5 \mathrm{~km}^{2}$ area. The horizontal free surface was composed of 15,400 triangular elements whose area was $7700 \mathrm{~km}^{2}$ (the distances along the NE-SW and SE-NW directions were 110 and $70 \mathrm{~km}$, respectively). Each free surface element had a $0.5 \mathrm{~km}^{2}$ area, which was the same as fault surface element size. The free surface was located at the upper margin of the non-planar fault. We first conducted many simulations for an infinite medium (i.e., without the free surface elements) to investigate the dependence of unknown parameters that will be described later. Then, we conducted simulations including the free surface elements for some parameters. The time interval for the dynamic rupture computation was $0.025 \mathrm{~s}$, which satisfies the

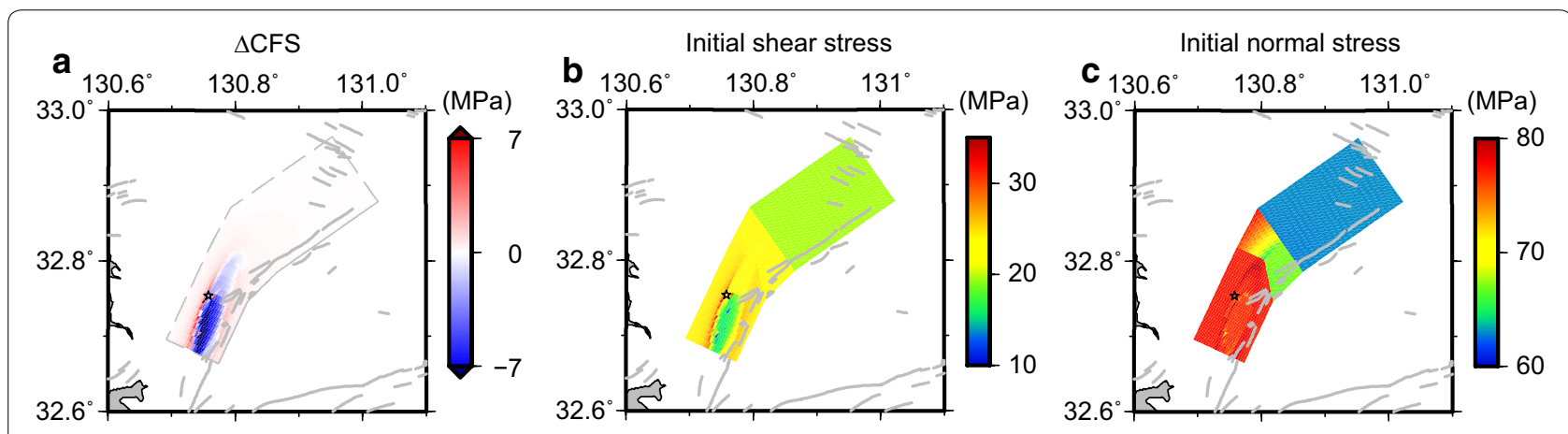

Fig. 5 a Coulomb failure stress change $(\triangle C F S)$ due to the three foreshocks, $\mathbf{b}$ initial shear stress, and $\mathbf{c}$ initial normal stress on a non-planar fault used in dynamic rupture simulations of the main shock. The initial stresses are the sum of the static stress changes due to the three foreshocks and the regional stress field for $\sigma_{1}=100 \mathrm{MPa}$ and $\sigma_{3}=50 \mathrm{MPa}$. The stars indicate the epicenter of the main shock obtained by Yoshida et al. (2016) 
Courant-Friedrichs-Lewy (CFL) condition (Tada and Madariaga 2001).

We set the directions of the principal stress axes, and the value of the stress ratio $R=\left(\sigma_{1}-\sigma_{2}\right) /\left(\sigma_{1}-\sigma_{3}\right)$, where $\sigma_{1}, \sigma_{2}$, and $\sigma_{3}$ are the maximum, intermediate, and minimum principal stresses, respectively, of the regional stress field; we also set the P- and S-wave velocities by referring to previous studies, as listed in Table 2. We estimated the $\mu_{\mathrm{d}}$ values (Table 3 ) from the regional stress field and the seismic moment using the relation between

Table 3 Estimated $\mu_{\mathrm{d}}$, assumed $\mu_{\mathrm{S}}$, and calculated $S$ and $L_{\mathrm{c}}$

\begin{tabular}{|c|c|c|c|c|c|c|c|c|c|c|c|c|}
\hline \multirow[t]{2}{*}{ Case name } & \multirow[t]{2}{*}{$\sigma_{1}$} & \multirow[t]{2}{*}{$\sigma_{3}$} & \multicolumn{2}{|l|}{$\sigma_{\mathrm{n}}^{r}(\mathrm{MPa})$} & \multicolumn{2}{|l|}{$\tau^{\mathrm{r}}(\mathrm{MPa})$} & \multirow[t]{2}{*}{$\mu_{\mathrm{d}}$} & \multirow[t]{2}{*}{$\mu_{\mathrm{s}}$} & \multicolumn{2}{|l|}{$S$} & \multicolumn{2}{|l|}{$L_{c}^{\mathrm{II}} / D_{\mathrm{c}}^{\mathrm{d}}$} \\
\hline & & & Hinagu & Futagawa & Hinagu & Futagawa & & & Hinagu $\left(S_{H}\right)$ & Futagawa & Hinagu & Futagawa \\
\hline \multirow[t]{5}{*}{ Case A } & 100 & 50 & 77.262 & 63.077 & 23.956 & 19.632 & 0.261 & - & $0.4^{\mathrm{a}}$ & - & - & - \\
\hline & & & & & & & & 0.349 & $0.8^{\mathrm{b}}$ & 0.758 & $6.3 \times 10^{3}$ & $7.4 \times 10^{3}$ \\
\hline & & & & & & & & 0.369 & $1.2^{c}$ & 1.148 & $7.8 \times 10^{3}$ & $9.1 \times 10^{3}$ \\
\hline & & & & & & & & 0.389 & 1.6 & 1.539 & $9.2 \times 10^{3}$ & $1.1 \times 10^{4}$ \\
\hline & & & & & & & & 0.408 & 2.0 & 1.930 & $1.1 \times 10^{4}$ & $1.2 \times 10^{4}$ \\
\hline \multirow[t]{5}{*}{ Case B } & 100 & 70 & 86.357 & 77.846 & 14.373 & 11.779 & 0.116 & 0.187 & 0.4 & 1.000 & $4.3 \times 10^{3}$ & $9.7 \times 10^{3}$ \\
\hline & & & & & & & & 0.207 & 0.8 & 1.571 & $5.5 \times 10^{3}$ & $1.2 \times 10^{4}$ \\
\hline & & & & & & & & 0.227 & 1.2 & 2.143 & $6.7 \times 10^{3}$ & $1.5 \times 10^{4}$ \\
\hline & & & & & & & & 0.247 & 1.6 & 2.714 & $8.0 \times 10^{3}$ & $1.8 \times 10^{4}$ \\
\hline & & & & & & & & 0.267 & 2.0 & 3.285 & $9.2 \times 10^{3}$ & $2.1 \times 10^{4}$ \\
\hline \multirow[t]{5}{*}{ Case C } & 300 & 160 & 236.334 & 196.616 & 67.076 & 54.969 & 0.266 & - & $0.4^{\mathrm{a}}$ & - & - & - \\
\hline & & & & & & & & - & $0.8^{\mathrm{a}}$ & - & - & - \\
\hline & & & & & & & & - & $1.2^{\mathrm{a}}$ & - & - & - \\
\hline & & & & & & & & 0.312 & 1.6 & 2.413 & $8.2 \times 10^{3}$ & $1.7 \times 10^{4}$ \\
\hline & & & & & & & & 0.319 & 2.0 & 2.938 & $9.5 \times 10^{3}$ & $2.0 \times 10^{4}$ \\
\hline \multirow[t]{5}{*}{ Case D } & 300 & 260 & 281.810 & 270.462 & 19.165 & 15.705 & 0.050 & 0.0752 & 0.4 & 2.12407 & $3.7 \times 10^{3}$ & $1.9 \times 10^{4}$ \\
\hline & & & & & & & & 0.0824 & 0.8 & 3.016662 & $4.7 \times 10^{3}$ & $2.5 \times 10^{4}$ \\
\hline & & & & & & & & 0.0896 & 1.2 & 3.909253 & $5.8 \times 10^{3}$ & $3.0 \times 10^{4}$ \\
\hline & & & & & & & & 0.0968 & 1.6 & 4.801845 & $6.8 \times 10^{3}$ & $3.5 \times 10^{4}$ \\
\hline & & & & & & & & 0.104 & 2.0 & 5.694436 & $7.9 \times 10^{3}$ & $4.1 \times 10^{4}$ \\
\hline \multirow[t]{5}{*}{ Case E } & 500 & 290 & 404.502 & 344.924 & 100.614 & 82.454 & 0.235 & - & $0.4^{\mathrm{a}}$ & - & - & - \\
\hline & & & & & & & & - & $0.8^{\mathrm{a}}$ & - & - & - \\
\hline & & & & & & & & 0.265 & 1.2 & 6.464 & $5.3 \times 10^{3}$ & $7.1 \times 10^{4}$ \\
\hline & & & & & & & & 0.271 & 1.6 & 7.822 & $6.2 \times 10^{3}$ & $8.4 \times 10^{4}$ \\
\hline & & & & & & & & 0.276 & 2.0 & 9.179 & $7.2 \times 10^{3}$ & $9.7 \times 10^{4}$ \\
\hline \multirow[t]{5}{*}{ Case F } & 500 & 400 & 454.525 & 426.154 & 47.912 & 39.264 & 0.090 & 0.112 & 0.4 & 9.106 & $2.7 \times 10^{3}$ & $1.5 \times 10^{5}$ \\
\hline & & & & & & & & 0.118 & 0.8 & 11.994 & $3.4 \times 10^{3}$ & $1.9 \times 10^{5}$ \\
\hline & & & & & & & & 0.124 & 1.2 & 14.881 & $4.2 \times 10^{3}$ & $2.3 \times 10^{5}$ \\
\hline & & & & & & & & 0.130 & 1.6 & 17.768 & $5.0 \times 10^{3}$ & $2.8 \times 10^{5}$ \\
\hline & & & & & & & & 0.136 & 2.0 & 20.656 & $5.7 \times 10^{3}$ & $3.2 \times 10^{5}$ \\
\hline \multirow[t]{5}{*}{ Case G } & 500 & 460 & 481.810 & 470.462 & 19.165 & 15.705 & 0.029 & 0.0441 & 0.4 & 2.442 & $3.6 \times 10^{3}$ & $2.2 \times 10^{4}$ \\
\hline & & & & & & & & 0.0484 & 0.8 & 3.426 & $4.6 \times 10^{3}$ & $2.9 \times 10^{4}$ \\
\hline & & & & & & & & 0.0527 & 1.2 & 4.409 & $5.7 \times 10^{3}$ & $3.5 \times 10^{4}$ \\
\hline & & & & & & & & 0.0570 & 1.6 & 5.393 & $6.7 \times 10^{3}$ & $4.1 \times 10^{4}$ \\
\hline & & & & & & & & 0.0613 & 2.0 & 6.376 & $7.7 \times 10^{3}$ & $4.8 \times 10^{4}$ \\
\hline
\end{tabular}

\footnotetext{
${ }^{a}$ We did not conduct simulations of these cases because $\mu_{\mathrm{s}}$ is smaller than $\mu^{r}=\tau^{r} / \sigma_{n}^{r}$ in the junction elements

${ }^{\mathrm{b}}$ The case with $D_{\mathrm{c}}$ of $0.35 \mathrm{~m}$ is referred to as case $\mathrm{A} 2$ in the text and figures

c The case with $D_{c}$ of $0.75 \mathrm{~m}$ is referred to as case $\mathrm{A} 1$ in the text and figures

${ }^{d} L_{c}^{\prime \prime}$ is $L_{c}$ for mode II
} 
the stress drop and the average slip of an elliptical crack by Madariaga (1977), taking into account the free surface effect. The details are described in "Appendix 2" section.

We assumed the magnitudes of two principal stresses (among $\sigma_{1}, \sigma_{2}$, and $\sigma_{3}$ ), $D_{\mathrm{c}}$, and $\mu_{\mathrm{s}}$. The maximum effective (i.e., after deducting the pore pressure) principal stress $\sigma_{1}$ was assumed to be either 100,300 , or $500 \mathrm{MPa}$. The lithostatic pressure became $260 \mathrm{MPa}$ at a depth of $10 \mathrm{~km}$ assuming the rock density shown in Table 2 . An excess of $\sigma_{1}$ over the lithostatic pressure corresponded to the tectonic loads. A $\sigma_{1}$ value of $100 \mathrm{MPa}$ was possible if the effective stress value was lowered by overpressurized fluids (e.g., Sibson 1992). The minimum principal stress $\sigma_{3}$ was set to be either 50 or $70 \mathrm{MPa}$ for cases with a $\sigma_{1}$ value of $100 \mathrm{MPa}$ (cases A and B, respectively), either 160 or $260 \mathrm{MPa}$ for cases with a $\sigma_{1}$ value of $300 \mathrm{MPa}$ (cases $\mathrm{C}$ and D, respectively), and either 290,400 , or $460 \mathrm{MPa}$ for cases with a $\sigma_{1}$ value of $500 \mathrm{MPa}$ (cases E, F, and G, respectively). It should be noted that $\sigma_{3}$ values that were smaller or larger than these values were found to be unacceptable from static computations. Figure 6 shows the yield stress $\mu_{\mathrm{s}} \sigma_{\mathrm{n}}^{\mathrm{r}}-\tau^{\mathrm{r}}$ and stress drop $\tau^{\mathrm{r}}-\mu_{\mathrm{d}} \sigma_{\mathrm{n}}^{\mathrm{r}}$ without stress perturbation induced by the foreshocks as functions of $\sigma_{3}$ when an $S$ value on the Hinagu fault $\left(S_{\mathrm{H}}\right)$ is 2.0, where $S=\left(\mu_{\mathrm{s}}-\mu^{\mathrm{r}}\right) /\left(\mu^{\mathrm{r}}-\mu_{\mathrm{d}}\right)$ (Andrews 1976b) and $\mu^{\mathrm{r}}=\tau^{\mathrm{r}} / \sigma_{\mathrm{n}}^{\mathrm{r}}$. For the small $\sigma_{3}$ value indicated by the light gray area in Fig. $6, \tau^{\mathrm{r}}$ was much higher on the Futagawa fault than that on the Hinagu fault, and thus, the moment release (i.e., stress drop) in the Futagawa fault should have been larger than the observed seismic moment even if the stress drop on the Hinagu Fault was zero. For the $\sigma_{3}$ value indicated by the dark gray area in Fig. 6 , the yield stress became negative; that is, ruptures must start on the Futagawa fault and/or at the junction. It should be noted that the range of $\sigma_{3}$ for the negative yield stress should extend when $S_{\mathrm{H}}$ is smaller than 2.0. For the large $\sigma_{3}$ value indicated by the gray area in Fig. $6, \tau^{\mathrm{r}}$ became smaller than $\Delta \tau^{\mathrm{f}}$; the slip direction must be opposite to the main slip direction in a part of the Hinagu fault. Therefore, we only considered the range of $\sigma_{3}$ values except those three regimes. $D_{\mathrm{c}}$ was assumed either $0.1,0.35,0.5,0.75,1.0$, or $1.5 \mathrm{~m}$. When $D_{\mathrm{c}}=0.1 \mathrm{~m}$, cohesive zone would not be resolved adequately because its size would be smaller than the element size, as stated in detail in "Discussion" section. The $\mu_{\mathrm{s}}$ value was set to satisfy that the value of $S_{\mathrm{H}}$ was either $0.4,0.8,1.2,1.6$, or 2.0 (Table 3 ).

\section{Results}

\section{Rupture processes in an infinite medium}

Figure 7 shows whether or not a rupture propagated from the Hinagu to the Futagawa fault successfully. When $\sigma_{1}$ and $\sigma_{3}$ were 100 and $50 \mathrm{MPa}$, respectively (case A, Fig. $7 \mathrm{a}$ ), the yield stress was negative (i.e., $\mu_{0}>\mu_{\mathrm{s}}$ ) in junction elements for cases with an $S_{\mathrm{H}}$ value smaller than 0.58 (gray area in Fig. 7a). Therefore, a larger $S_{\mathrm{H}}$ was feasible. No rupture was initiated for a $D_{\mathrm{c}}$ value longer than $0.75 \mathrm{~m}$, regardless of the value of $S_{\mathrm{H}}$, because of the long $L_{\mathrm{c}}$ (longer than $4.7 \mathrm{~km}$ for mode II, Table 3 ) and of the stress shadow due to the foreshocks (i.e., the large negative $\Delta$ CFS). When $D_{\mathrm{c}}$ was $0.75 \mathrm{~m}$ and $S_{\mathrm{H}}$ was 1.2 (case A1), a rupture propagated on the Hinagu fault at depth, but it terminated on the Futagawa fault, as shown in Fig. 8a. The rupture terminated because of the stress shadow on the Hinagu fault caused by the foreshocks. It interfered with the rupture propagation toward the shallow part of the Hinagu fault. In addition, the rupture propagation on the Futagawa fault was prevented by a longer critical length $L_{\mathrm{c}}$ on the Futagawa fault than on the Hinagu fault, as shown in Table 3.

When $D_{\mathrm{c}}$ was shorter than $0.75 \mathrm{~m}$, on the other hand, a rupture propagated successfully to the Futagawa fault, regardless of $S_{\mathrm{H}}$ values. Figure $8 \mathrm{~b}$ shows the results for the case with $D_{\mathrm{c}}$ and $S_{\mathrm{H}}$ values of $0.35 \mathrm{~m}$ and 0.8 , respectively (case A2). In this case, the rupture was initiated spontaneously at a slightly deeper part than the hypocenter on the Hinagu fault due to the high $\triangle$ CFS (Fig. 5a). It then propagated toward the Futagawa fault at depth and subsequently toward the shallow portion of the Hinagu fault. The small slip occurred in the large negative $\triangle$ CFS region of the Hinagu fault (Fig. 5a), but a part of the region was not ruptured. We will discuss the spontaneous initiation of the rupture and its depth in the next section.

When $\sigma_{1}$ and $\sigma_{3}$ were 100 and $70 \mathrm{MPa}$, respectively (case B, Fig. 7b), the yield stress was positive on the whole fault plane even for cases with an $S_{\mathrm{H}}$ value of 0.4, unlike case A. However, the high $\triangle$ CFS (Fig. $5 \mathrm{a}$ ) due to the foreshocks triggered ruptures not only at the hypocenter of the main shock but also at a shallow part for cases with an $S_{\mathrm{H}}$ value of 0.4 (blue and light blue circles in Fig. $7 \mathrm{~b}$ ). Therefore, a larger $S_{\mathrm{H}}$ was feasible. The rupture propagated successfully from the Hinagu fault to the Futagawa fault when $D_{\mathrm{c}}$ was $0.5 \mathrm{~m}$ or shorter for $S_{\mathrm{H}}=0.8$ and $0.1 \mathrm{~m}$ for larger $S_{\mathrm{H}}$ values, although cohesive zone would not be resolved adequately in the cases with $D_{\mathrm{c}}=0.1 \mathrm{~m}$.

When $\sigma_{1}$ was $300 \mathrm{MPa}$, the rupture propagated successfully from the Hinagu fault to the Futagawa fault with less number of combinations of $D_{\mathrm{c}}$ and $S_{\mathrm{H}}$. When $\sigma_{3}$ was $160 \mathrm{MPa}$ (Case C, Fig. 7c), $S_{\mathrm{H}}$ values equal to or smaller than 1.24 were not feasible because of the negative yield stress in junction elements (gray area in Fig. 7c). The rupture propagated successfully for cases with $D_{\mathrm{c}}$ smaller than $0.5 \mathrm{~m}$. When $\sigma_{3}$ was $260 \mathrm{MPa}$ (Case D, Fig. $7 \mathrm{~d}$ ), the feasible parameter sets were $D_{\mathrm{c}}$ of $0.1 \mathrm{~m}$ and $S_{\mathrm{H}}$ of either 0.8 or 1.2 , although cohesive zone would not be resolved adequately in these cases. An $S_{\mathrm{H}}$ value of 0.4 was not acceptable because 

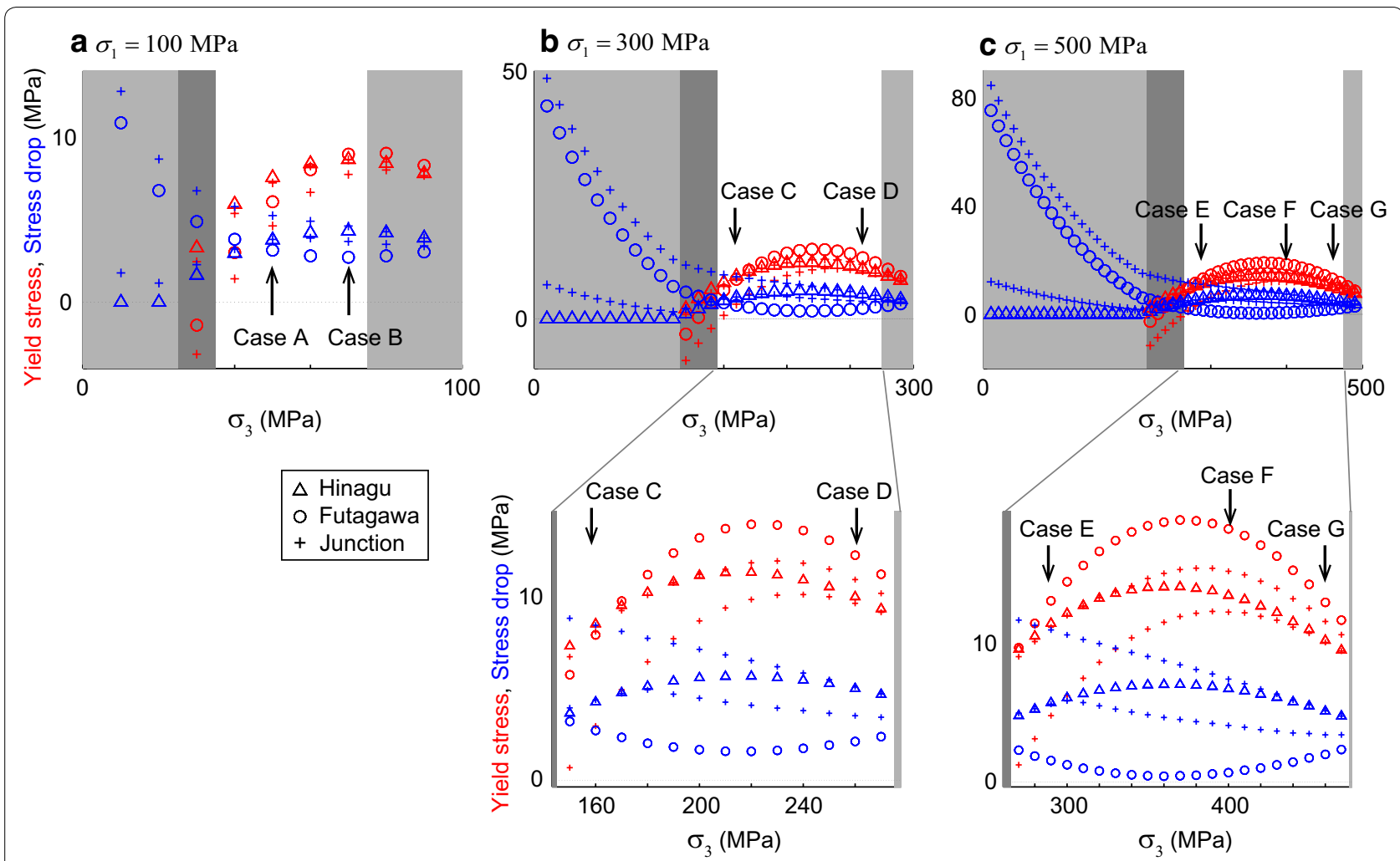

Fig. 6 Yield stresses (red) and stress drops (blue) as a function of $\sigma_{3}$ for a $\sigma_{1}$ value of $\mathbf{a} 100, \mathbf{b} 300$, and $\mathbf{c} 500 \mathrm{MPa}$. SH was set to be 2.0 in the calculations of the yield stresses. Triangles and circles indicate the values of the Hinagu and Futagawa faults, respectively. Crosses indicate the maximum and minimum values of the junction elements for each $\sigma_{3}$. For low $\sigma_{3}$ values indicated in light gray, $\tau^{\Upsilon}$ is much higher on the Futagawa fault than on the Hinagu fault, and thus, the seismic moment (i.e., stress drop) in the Futagawa fault should have been larger than the observed seismic moment even if the stress drop on the Hinagu Fault is zero. For low $\sigma_{3}$ values indicated in dark gray, the yield stress is negative. For high $\sigma_{3}$ values indicated in gray, the regional shear stress $\tau^{\mathrm{r}}$ is smaller than the static shear stress change due to the three foreshocks. Therefore, white regions correspond to the feasible $\sigma_{3}$ values. The bottom panels are enlarged figures of the white region in the top panels

the high $\triangle$ CFS (Fig. 5a) due to the foreshocks triggered ruptures not only at the hypocenter of the main shock but also at a shallow part of the Hinagu fault (blue and light blue symbols in Fig. $7 \mathrm{~d}$ ). If $\sigma_{3}$ is between these two values, the strength excess is higher and the stress drop is lower than cases C and D on the Futagawa fault (Fig. 6b); thus, the rupture is unlikely to propagate to the Futagawa fault.

When $\sigma_{1}$ was $500 \mathrm{MPa}$ (cases E, F, and G; Fig. 7e, f, g), the rupture propagated successfully only for cases with $\sigma_{3}$ of $460 \mathrm{MPa}$ (case G), $D_{\mathrm{c}}$ of $0.1 \mathrm{~m}$, and $S_{\mathrm{H}}$ of either 0.8 or 1.2, although cohesive zone would not be resolved adequately in these cases. In all cases with a $\sigma_{3}$ of 290 and $400 \mathrm{MPa}$ (cases $\mathrm{E}$ and $\mathrm{F}$ ), a rupture was not initiated or it was initiated but terminated shortly. The rupture propagation on the Futagawa fault was prevented by the larger strength excess and the smaller stress drop, and thus the larger $S$ and the longer $L_{\mathrm{c}}$, on the Futagawa fault than on the Hinagu fault (Fig. $6 \mathrm{c}$ and Table 3). For the cases in which $300 \leq \sigma_{3} \leq 440 \mathrm{MPa}$ (including case $\mathrm{F}$ ), the stress drop $\tau^{\mathrm{r}}-\mu_{\mathrm{d}} \sigma_{\mathrm{n}}^{\mathrm{r}}$ on the Futagawa fault was lower than $1.5 \mathrm{MPa}$ (lower panel of Fig. 6b). Thus, the large slip on the Futagawa fault that was observed by the seismic waveform analyses (Asano and Iwata 2016; Kubo et al. 2016; Uchide et al. 2016; Yagi et al. 2016; Kobayashi et al. 2017; Hao et al. 2017) as well as in the geodetic data (Himematsu and Furuya 2016) would not be produced, even if the $D_{\mathrm{c}}$ and $S_{\mathrm{H}}$ values are smaller than those used in this study. If $D_{\mathrm{c}}$ is much smaller than $0.1 \mathrm{~m}$ in case $\mathrm{E}$, the rupture might transfer to the Futagawa fault. However, $D_{c} \ll 0.1 \mathrm{~m}$ is much smaller than the value $(1 \mathrm{~m})$ estimated from the near-fault seismic waveforms by Fukuyama and Suzuki (2016).

Thus, the feasible parameters with which to reproduce the dynamic rupture of this earthquake are as follows: $\sigma_{1}=100 \mathrm{MPa}, \quad 40 \leq \sigma_{3} \leq 70 \mathrm{MPa}, D_{\mathrm{c}} \leq 0.75 \mathrm{~m}$, $S_{\mathrm{H}} \geq 0.8$; for $\sigma_{1}=300 \mathrm{MPa},\left(\sigma_{3}=160 \mathrm{MPa}, D_{\mathrm{c}} \leq 0.35 \mathrm{~m}\right.$, $\left.S_{\mathrm{H}} \geq 1.6\right)$ or $\left(\sigma_{3}=260 \mathrm{MPa}, D_{\mathrm{c}}=0.1 \mathrm{~m}, 0.8 \leq S_{\mathrm{H}} \leq 1.2\right)$; 
a Case $\mathrm{A}$

$\left(\sigma_{1}=100 \mathrm{MPa}, \sigma_{3}=50 \mathrm{MPa}\right)$

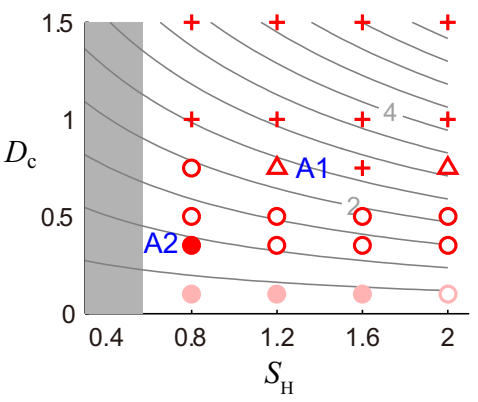

c Case C

$\left(\sigma_{1}=300 \mathrm{MPa}, \sigma_{3}=160 \mathrm{MPa}\right)$

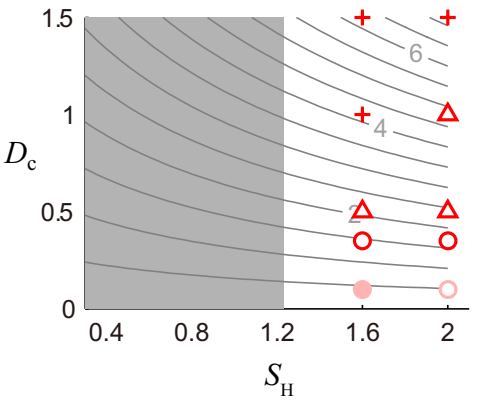

e Case $\mathrm{E}$

$\left(\sigma_{1}=500 \mathrm{MPa}, \sigma_{3}=290 \mathrm{MPa}\right)$

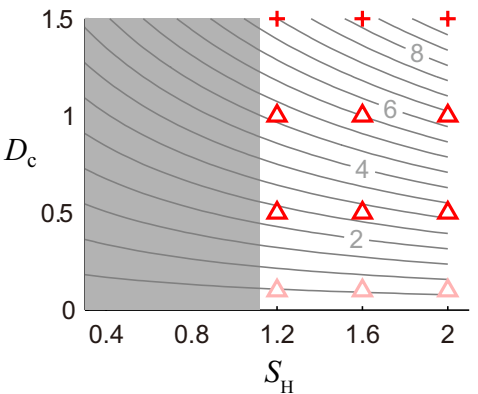

b Case $B$

$\left(\sigma_{1}=100 \mathrm{MPa}, \sigma_{3}=70 \mathrm{MPa}\right)$

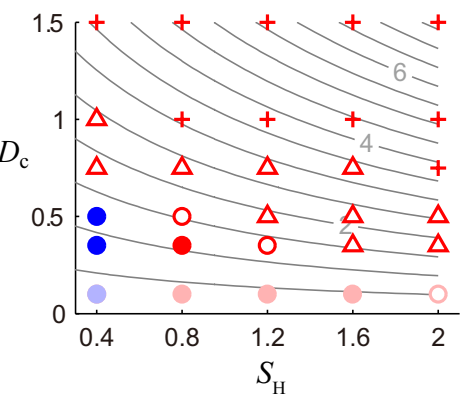

d Case D

$\left(\sigma_{1}=300 \mathrm{MPa}, \sigma_{3}=260 \mathrm{MPa}\right)$

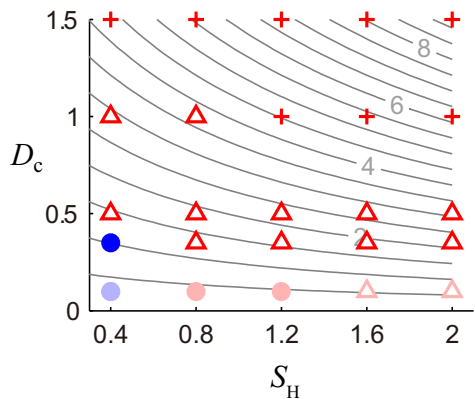

f Case $\mathrm{F}$

$\left(\sigma_{1}=500 \mathrm{MPa}, \sigma_{3}=400 \mathrm{MPa}\right)$

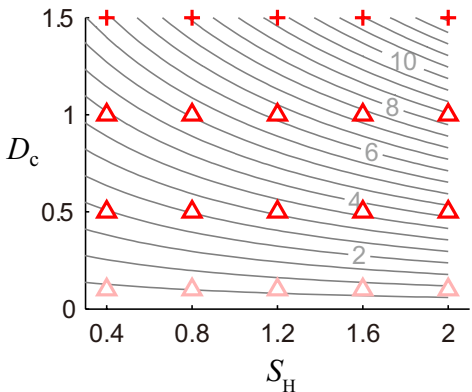

g Case G $\left(\sigma_{1}=500 \mathrm{MPa}, \sigma_{3}=460 \mathrm{MPa}\right)$

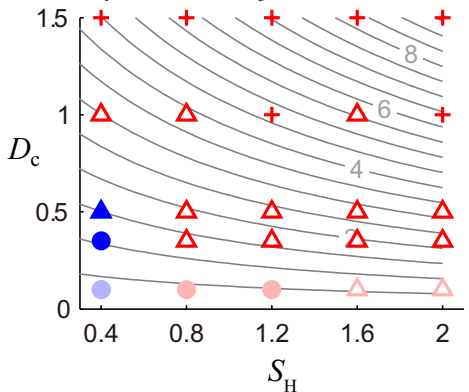

Fig. 7 Results of many numerical simulations with various friction parameters $S_{H}$ and $D_{c}$. Circles indicate that a rupture propagated successfully. Triangles indicate that a rupture was initiated but terminated shortly. Crosses indicate that no rupture was initiated. A rupture started spontaneously from the high $\triangle C F S$ regions on the Hinagu fault without the artificial shear stress increase in the cases indicated by the solid symbols. Among these cases, the blue and light blue symbols indicate that the high $\triangle C F S$ triggered ruptures not only at the hypocenter of the main shock but also at a shallow part of the Hinagu fault. In the other cases, a rupture was forced to be initiated by artificially increasing shear stress. In the cases shown by the light red and light blue symbols, the cohesive zone may not be resolved. For small $S_{H}$ values indicated by gray, $\mu_{s}$ is $s$ maller than $\mu^{r}=\tau^{r} / \sigma_{n}^{r}$ in junction elements. Contours show the fracture energy $G_{c}$ integrated on the whole fault plane (unit is $10^{15} \mathrm{Nm}$ ), calculated by using $\sigma_{n}^{0}$ values. In the computations, a non-planar fault is in the infinite medium (i.e., without a free surface). $\sigma_{1}$ is $100 \mathrm{MPa}$ and $\sigma_{3}$ is $\mathbf{a} 50 \mathrm{MPa}$ (case A) and $\mathbf{b} 70 \mathrm{MPa}$ (case B), $\sigma_{1}$ is $300 \mathrm{MPa}$ and $\sigma_{3}$ is $\mathbf{c} 160 \mathrm{MPa}$ (case C) and $\mathbf{d} 260 \mathrm{MPa}$ (case D), and $\sigma_{1}$ is $500 \mathrm{MPa}$ and $\sigma_{3}$ is $\mathbf{e} 290 \mathrm{MPa}$ (case E), $\mathbf{f} 400 \mathrm{MPa}$ (case F), and $\mathbf{g}$ $460 \mathrm{MPa}$ (case G)

$\sigma_{1}=500 \mathrm{MPa}$,

$0.8 \leq S_{\mathrm{H}} \leq 1.2$

\section{Free surface effect}

In this section, we investigate the free surface effect for case A2 $\left(\sigma_{1}=100 \mathrm{MPa}, \sigma_{3}=50 \mathrm{MPa}, D_{\mathrm{c}}=0.35 \mathrm{~m}\right.$, and $S_{\mathrm{H}}=0.8$ ). The rupture time was similar to that in the case without the free surface (Figs. 8b, 9a). The slip amount near the free surface initially became larger than that in the case without the free surface, as shown in the panel labeled " $8-10 \mathrm{~s}$ " in Fig. 9b, and the final slip amount was larger and the maximum slip was observed 


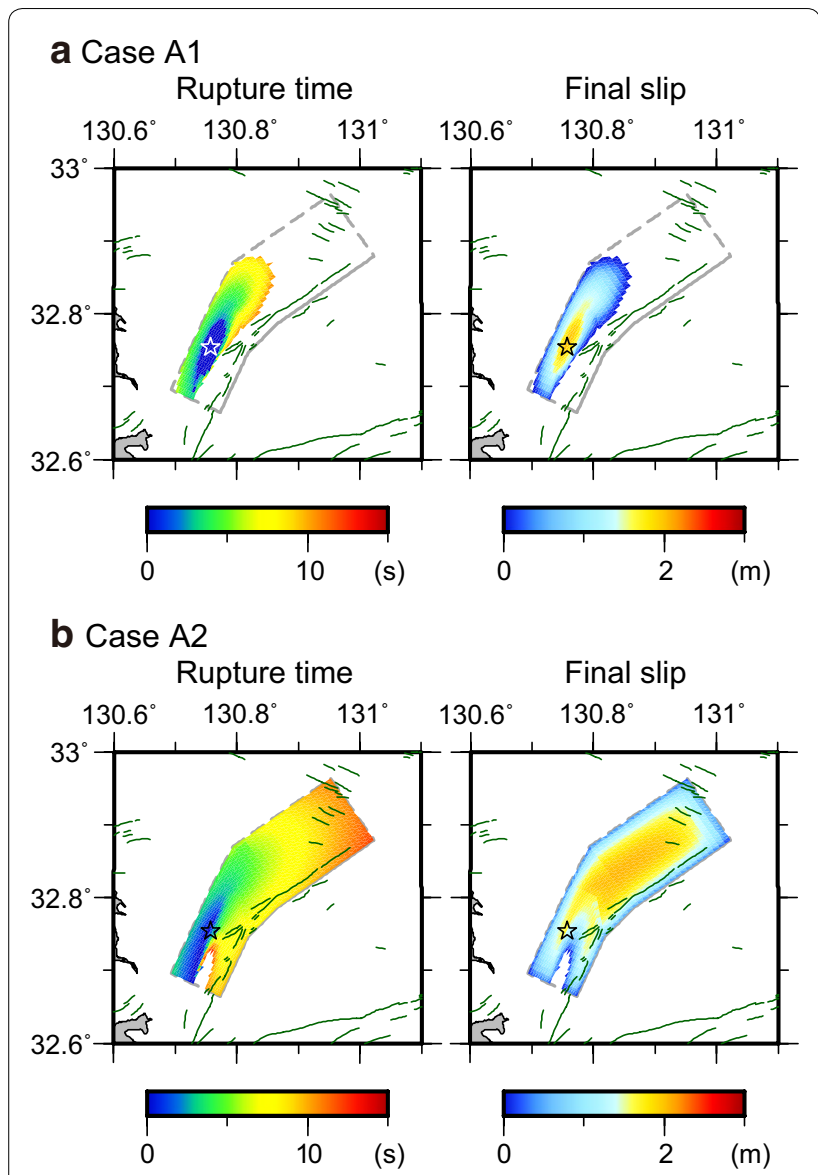

Fig. 8 Rupture time (left panels) and final slip distribution (right panels) in cases $\mathbf{a} \mathrm{A} 1$ and $\mathbf{b} \mathrm{A} 2$ without the free surface

at a shallower depth than in the case without the free surface (Figs. 8b, 9c).

Thus, a free surface would have promoted the rupture propagation and played an important role in the rupture process of the 2016 Kumamoto earthquake.

\section{Discussion}

The features of the rupture propagation in case A2 with the free surface were consistent with the observations summarized in "Introduction" section. The seismic moment was $4.9 \times 10^{19} \mathrm{Nm}$, similar to the observed one (Table 1 ). The maximum slip amount was $\sim 4 \mathrm{~m}$ in the shallow region of the Futagawa fault (Fig. 9c), consistent with the results of the inversion analyses of the seismic waveform and geodetic data. The rupture propagated from the Hinagu fault to the Futagawa fault at a depth of $\sim 15 \mathrm{~km}$ at $4 \mathrm{~s}$. Then, the large slip occurred on the Futagawa fault at mid-depth for 6-10 s, and on the shallow region of the Futagawa fault for 9-12 s (Fig. 9b). These temporal evolutions of rupture were similar to the results of the seismic waveform analyses. The synthetic moment rate function was $8.1 \times 10^{18} \mathrm{Nm} / \mathrm{s}$ at maximum at $10 \mathrm{~s}$ with the duration of $18 \mathrm{~s}$ (Fig. 9d). The peak time and the duration were similar to the observed ones. The rupture on both the Hinagu and Futagawa faults reached the free surface, and the slip amount near the free surface was larger on the Futagawa fault than on the Hinagu fault and in the junction (Fig. 9c); these features were consistent with the field observations of the surface rupture. Thus, the parameter set of case A2 $\left(\sigma_{1}=100 \mathrm{MPa}, \sigma_{3}=50 \mathrm{MPa}, D_{\mathrm{c}}=0.35 \mathrm{~m}\right.$, and $\left.S_{\mathrm{H}}=0.8\right)$ was feasible.

The combinations of the shorter $D_{\mathrm{c}}$ and the larger $S_{\mathrm{H}}$ than in case A2 under the same stress condition (case A) were also feasible. When $D_{\mathrm{c}}$ was $0.1 \mathrm{~m}$, the features of the rupture propagation in cases with $S_{\mathrm{H}}$ of either 1.2 or 1.6 were similar to the observations summarized in "Introduction" section. We cannot obtain the unique combination of feasible $D_{\mathrm{c}}$ and $S_{\mathrm{H}}$ because there is a trade-off between $S_{\mathrm{H}}$ and $D_{\mathrm{c}}$ in $L_{\mathrm{c}}$ and in the fracture energy $G_{\mathrm{c}}=\frac{1}{2} \int\left(\mu_{\mathrm{s}}-\mu_{\mathrm{d}}\right) \sigma_{\mathrm{n}} D_{\mathrm{c}} \mathrm{d} A$ (Andrews 1976a, b), which controls the rupture velocity. $G_{\mathrm{c}}$ integrated on the whole fault plane is shown by the contours in Fig. 7, which was calculated under the assumption of temporary constant (but spatially non-uniform) $\sigma_{\mathrm{n}}$.

The other parameter sets of $D_{\mathrm{c}}$ and $S_{\mathrm{H}}$ did not reproduce the observed features, as described in detail in Additional file 1: Text S1. A rupture did not propagate or evolve too slowly, compared to the observation, in case A with $G_{\mathrm{C}}$ larger than $10^{15} \mathrm{Nm}$. For example, in case A1 $\left(D_{\mathrm{c}}=0.75 \mathrm{~m}\right.$ and $\left.S_{\mathrm{H}}=1.2\right)$, the rupture propagated on the Hinagu fault at depth but terminated, even if the free surface was taken into account. When $D_{\mathrm{c}}$ was $0.35 \mathrm{~m}$ and $S_{\mathrm{H}}$ was 1.2 , the rupture propagated more slowly than in the observation, as shown in Additional file 1: Figure S1. In the case with $D_{\mathrm{c}}$ of $0.1 \mathrm{~m}$ and $S_{\mathrm{H}}$ of 0.8 , on the other hand, $G_{C}$ was smaller than in the cases with the feasible parameters, and the rupture evolved faster than the observation (Additional file 1: Figure S2). Thus, these parameter sets were not feasible.

The same combinations of $D_{\mathrm{c}}$ and $S_{\mathrm{H}}$ were feasible in case $\mathrm{B}\left(\sigma_{1}=100 \mathrm{MPa}\right.$ and $\left.\sigma_{3}=70 \mathrm{MPa}\right)$ as in case A $\left(\sigma_{1}=100 \mathrm{MPa}\right.$ and $\left.\sigma_{3}=50 \mathrm{MPa}\right)$. When $\sigma_{1}$ was either 300 or $500 \mathrm{MPa}$, on the other hand, final slip distribution was not similar to the observed one, as stated in detail in Additional file 1: Text S1. Thus, $\sigma_{1}$ was likely to be low $(\sim 100 \mathrm{MPa})$.

The slip amount in the stress shadow (the large negative $\triangle$ CFS in Fig. 5a) on the Hinagu fault was very small, and a part of the stress shadow was not ruptured in our simulations. Yagi et al. (2016) estimated very small shear stress change in the shallow region of the southwest of the hypocenter from their teleseismic slip inversion results. This is more or less consistent with the stress 

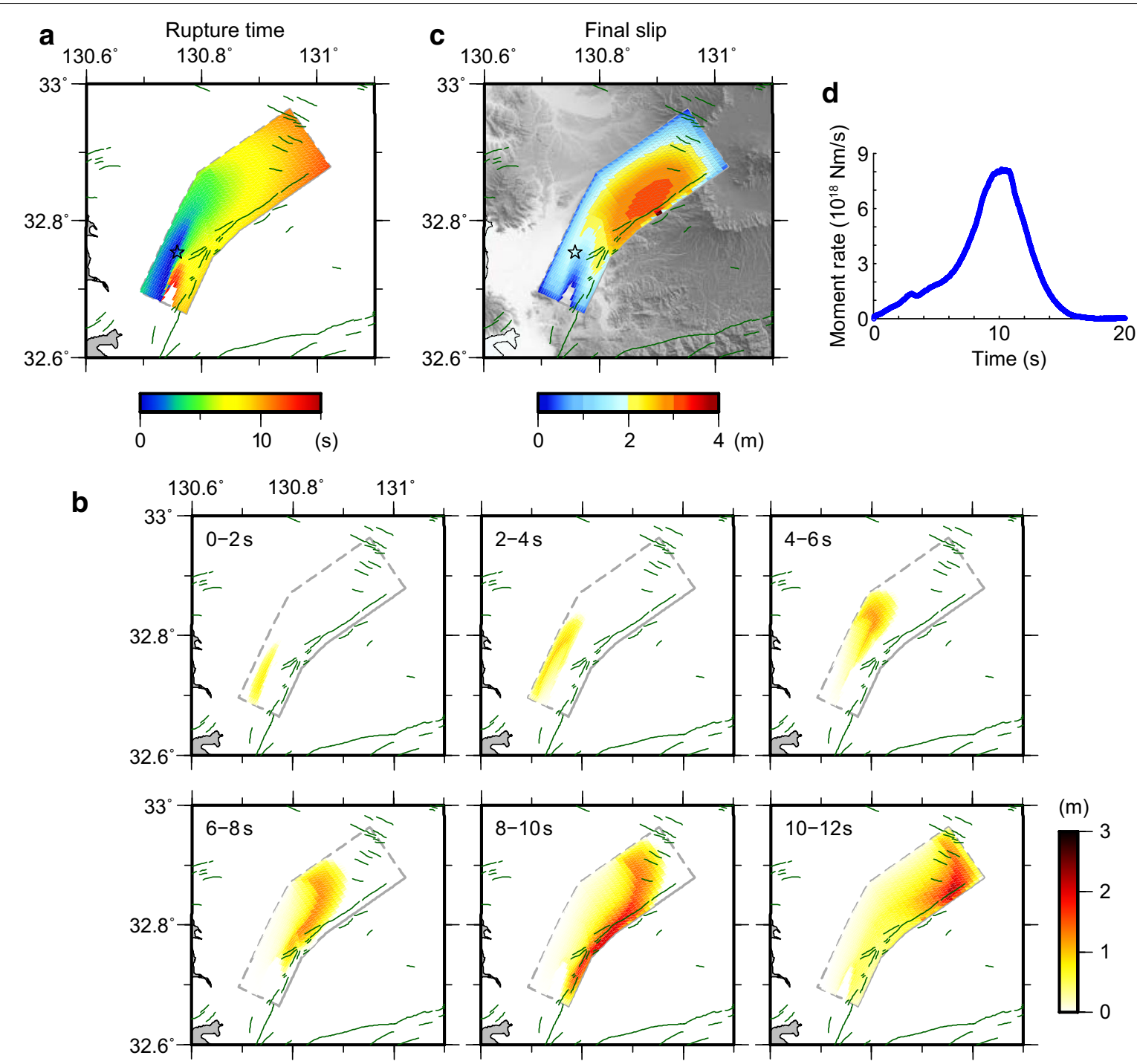

Fig. 9 a Rupture time, $\mathbf{b}$ slip amount for each 2-s time window, c final slip distribution, and $\mathbf{d}$ moment rate function in case A2 with the free surface. Note that the color scale in $\mathbf{c}$ is different from that in right panels of Fig. 8

shadow zone in this study. The other waveform inversion results also detected small slip in that region (Asano and Iwata 2016; Kubo et al. 2016; Uchide et al. 2016; Kobayashi et al. 2017). This could result from the small stress drop in that area.

The peak value of the moment rate function was 30\% higher in case A2 with the free surface than that obtained by Yagi et al. (2016) and Hao et al. (2017). The high peak value resulted from the large slip near the free surface in the panels labeled " $8-10 \mathrm{~s}$ " and "10-12 s" in Fig. 9b. If a longer $D_{\mathrm{c}}$, higher $\mu_{\mathrm{s}}$ (i.e., higher yield stress), or higher $\mu_{\mathrm{d}}$ (i.e., lower stress drop) in a shallow region is assumed, the peak value would become lower and consistent with the observed one.
A rupture started and propagated spontaneously from the high $\triangle C F S$ regions on the Hinagu fault, which were dominantly induced by the slip of foreshock 1 , without the artificial shear stress increase, in some cases including case A2 as shown by the solid symbols in Fig. 7. However, the main shock occurred $28 \mathrm{~h}$ after foreshock 1 . The contradiction might come from the estimation error of the geometry of the fault planes, from the assumption of the uniform regional stress, and from simpler slip distribution of foreshock 1 assumed in "Static stress changes by foreshocks" section than that estimated by waveform inversions (Kubo et al. 2016; Asano and Iwata 2016; Kobayashi et al. 2017). The delay of the main shock could be explained by aseismic slip, as suggested by Kato et al. 
(2016a). We will discuss the effect of the aseismic slip later. The initiation point of the rupture was slightly deeper than the relocated hypocenter by Yoshida et al. (2016).

Fukuyama and Suzuki (2016) obtained a $D_{c}^{\prime \prime}$ of $1 \mathrm{~m}$ as a proxy for $D_{\mathrm{c}}$ from the analyses of the near-fault seismic waveforms. Their estimate could be related to the $D_{\mathrm{c}}$ value at shallow depth near the KMMH16 station. However, in our simulations for $D_{\mathrm{c}} \geq 0.5 \mathrm{~m}$, the slip did not propagate to the Futagawa fault or evolved much more slowly compared to the seismic observation summarized in "Introduction" section. This discrepancy may partly come from the assumption of a constant $D_{\mathrm{c}}$ in our simulations. A $D_{\mathrm{c}}$ deeper than a few kilometers should be shorter than $0.5 \mathrm{~m}$ to reproduce the features of the rupture propagation as stated above, while a $D_{\mathrm{c}}$ in a shallow part could be larger.

A $\sigma_{1}$ value of $100 \mathrm{MPa}$ is lower than the lithostatic pressure except near the free surface. The small $\sigma_{1}$ is consistent with the low magnitude of the shear stress suggested by rotation of the principal stress axes due to the main shock (Yoshida et al. 2016). A possible explanation for the small $\sigma_{1}$ is the existence of overpressured fluids (e.g., Sibson 1992), which lowered the effective stress value.

We compared the observed near-fault ground displacements at KMMH16 (KiK-net), 93048, and 93049 (deployed by the local government of Kumamoto prefecture) stations with the synthetic results of case A2 with the free surface, as shown in Additional file 1: Figure S4. The locations of the stations are shown in Fig. 1. The synthetic polarity of the fault-parallel and vertical components of the displacement waveforms at all the stations and of the fault-normal component at 93049 was consistent with the observation. The synthetic faultnormal displacement at KMMH16 was much smaller than the observed ones, and the synthetic polarity of the static fault-normal component at 93048 was opposite to the observation. These inconsistencies may arise from the small differences in the local fault geometry and in the location of large slip between the model and the real because the polarity of the fault-normal component is sensitive to the site location relative to the fault slip. We simply assumed a rectangular fault plane for each of the Hinagu and Futagawa fault segments ("Estimation of fault planes" section). The synthetic seismic waves arrived at 93049 for a few seconds later than the observed ones. This may be because the stress shadow effect was slightly overestimated and the rupture delayed in the stress shadow zone. We did not focus on the reproduction of the observed seismograms in this study because we assumed uniform P- and S-wave velocities in the simulations, but this assumption was too simple to reproduce the near-fault site effect mentioned in the observations (Yamanaka et al. 2016). In addition, the element size $\left(0.5 \mathrm{~km}^{2}\right)$ might be too large to represent the surface movement by the fault.

Cohesive zone size should be the order of $\left(\frac{\mu D_{\mathrm{c}}}{\Delta \sigma}\right)^{2} \frac{1}{L}$, where $\mu$ is the rigidity, $\Delta \sigma$ is the stress drop, and $L$ is the distance that rupture has propagated, as shown by Andrews (2004). This size is longer than $10^{3} \mathrm{~m}$ when $L$ is $10 \mathrm{~km}$ in cases A1 and A2 $\left(D_{\mathrm{c}} \geq 0.35 \mathrm{~m}\right)$. Indeed, the cohesive zone was resolved adequately in these cases. However, the size is $\sim 90 \mathrm{~m}$ in cases with $D_{\mathrm{c}}=0.1 \mathrm{~m}$, which is smaller than the element size; therefore, the cohesive zone may not be resolved. The results of these cases may correspond to cases with $D_{\mathrm{c}}$ longer than $0.1 \mathrm{~m}$ (but smaller than $0.35 \mathrm{~m}$ ). Much smaller element size $(\sim 1 / 10$ of that in this study) is necessary for resolving the small cohesive zone. We could not conduct such simulations because of huge memory costs and computation time.

Kato et al. (2016a) reported the migrations of seismicity fronts along the directions of the fault strike and dip, starting immediately after foreshock 1 . They interpreted these migrations to result from aseismic slip triggered by foreshock 1 , propagating toward the nucleation point of the subsequent main shock rupture. They estimated a spatially uniform slip on a rectangular fault plane equivalent to an $M_{w} 5.8$ earthquake in order to reproduce the transient displacements observed in Global Navigation Satellite System (GNSS) data after foreshock 1 at two stations close to its fault plane, assuming the same fault geometry and slip direction as suggested by Kato et al. (2016b) for both foreshocks 1 and 3. To demonstrate the effect of the aseismic slip on the main shock rupture and on our results stated above, we first calculated the static stress changes due to the aseismic slip and then conducted the dynamic rupture simulations of case A2 with the free surface, taking into account the static stress changes due to the aseismic slip as well as the foreshocks. We assumed an elliptical crack for the aseismic slip in the same manner as for the foreshocks, and the same seismic moment of the aseismic slip as suggested by Kato et al. (2016a). The details of the model setup and of the results are shown in Additional file 1: Text S2. The results showed that the stress shadow was generated in the shallower portions of the Hinagu fault by the aseismic slip than by the foreshocks. The $\triangle \mathrm{CFS}$ was positive at and near the hypocenter of the main shock; therefore, the aseismic slip would have encouraged the rupture initiation of the main shock and may be able to explain the delay for $28 \mathrm{~h}$ of the main shock from foreshock 1 , as pointed out by Kato et al. (2016a). The static stress changes induced by the aseismic slip, however, were smaller than those by the foreshocks because of its smaller accumulated seismic moment until the main 
shock. The features of the rupture propagation were similar between the cases with and without the static stress change induced by the aseismic slip. Thus, our results on the rupture propagation and on the feasible parameters stated above were not affected by the aseismic slip.

\section{Conclusions}

We conducted 3-D dynamic rupture simulations of the main shock of the 2016 Kumamoto, Japan, earthquake under an initial stress distribution constructed using the sum of the static stress changes induced by M6-class foreshocks and the regional stress field. We showed that the feasible parameter ranges that can reproduce the characteristic features of the main shock rupture revealed by seismic analyses were $\sigma_{1}=100 \mathrm{MPa}, 40 \leq \sigma_{3} \leq 70 \mathrm{MPa}$, $D_{\mathrm{c}}=0.35 \mathrm{~m}, \mu_{\mathrm{s}}=0.349$, and $\mu_{\mathrm{d}}=0.261\left(S_{\mathrm{H}}=0.8\right)$. The combinations of shorter $D_{\mathrm{c}}$ and larger $\mu_{\mathrm{s}}$ were also feasible under the same stress condition. With the parameters defined as $\sigma_{1}=100 \mathrm{MPa}, \sigma_{3}=50 \mathrm{MPa}, D_{\mathrm{c}}=0.35 \mathrm{~m}$, $\mu_{\mathrm{s}}=0.349$, and $\mu_{\mathrm{d}}=0.261\left(S_{\mathrm{H}}=0.8\right)$ (case A2), a rupture started where $\triangle \mathrm{CFS}$ was positive on the Hinagu fault at depth. The rupture then transferred to the Futagawa fault at depth and propagated toward a shallow part of the Hinagu fault. The largest slip occurred at a shallow part of the Futagawa fault. The slip in the stress shadow zone (a large negative $\Delta$ CFS) on the Hinagu fault was very small. These rupture propagation features were consistent with those obtained by the analyses of seismic waveforms and geodetic data, and by field investigations. We also demonstrated that the free surface encouraged the slip evolution of the main shock.

\section{Additional file}

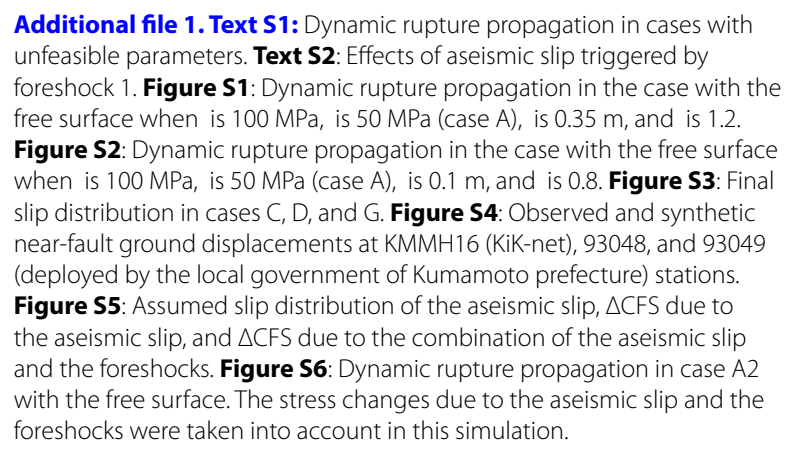

\section{Authors' contributions}

YU estimated the static stress changes due to the foreshocks and conducted the numerical simulations. KY analyzed the data to estimate the fault planes. EF participated in the design of the study and the discussion. EF and HK analyzed the seismic waveform data. YU and KY drafted the manuscript. All authors read and approved the final manuscript.

\section{Author details}

${ }^{1}$ National Research Institute for Earth Science and Disaster Resilience (NIED), 3-1 Tennodai, Tsukuba, Ibaraki 305-0006, Japan. ${ }^{2}$ Research Center for Prediction of Earthquakes and Volcanic Eruptions, Tohoku University, 6-6 Aza-Aoba, Aramaki, Aoba-ku, Sendai 980-8578, Japan.

\section{Acknowledgements}

This study was supported by the NIED project entitled "Source Mechanism of Large Earthquakes," the JAMSTEC-supported project entitled "Earthquake Modeling in Nankai Trough," and JSPS KAKENHI Grant Number JP16H06477. Waveform data were provided by the KiK-net maintained by the National Research Institute for Earth Science and Disaster Resilience and by Kumamoto prefectural government through the Japan Meteorological Agency. Generic Mapping Tools (Wessel and Smith 1998) was used to draw the figures. The 10-m mesh DEM published by the Geospatial Information Authority of Japan was used. We appreciate Editor Ryosuke Ando and two anonymous reviewers for their useful comments to improve our manuscript.

\section{Competing interests}

The authors declare that they have no competing interests.

\section{Appendix 1: Assumption of the slip distributions of the foreshocks}

Here we consider elliptical cracks with constant stress drops to obtain the slip distributions of the three foreshocks. The axes of the ellipse with an aspect ratio of $a / b$ correspond to the $x$ - and $y$-axes, respectively. The quantities $2 a$ and $2 b$ represent the length and width of each fault plane estimated in "Estimation of fault planes" section. The slip direction parallel to the $x$-axis is shown in Table 1. The slip distribution of the elliptical crack with the constant stress drop $\Delta \sigma$ (Eshelby 1957) is

$$
D(x, y)=\frac{2 b \Delta \sigma}{C_{1} \mu} \sqrt{1-\frac{x^{2}}{a^{2}}-\frac{y^{2}}{b^{2}}},
$$

where $\mu$ is the rigidity, $C_{1}$ is

$\begin{array}{ll}C_{1}=E(k)+\frac{v}{1-\nu} \frac{K(k)-E(k)}{k^{2}} ; & a>b, k=\sqrt{1-(b / a)^{2}} \\ =\frac{b}{a}\left[E(k)+\frac{v}{1-\nu} \frac{K(k)-(a / b)^{2} E(k)}{k^{2}}\right] ; & b>a, k=\sqrt{1-(a / b)^{2}},\end{array}$

$E(k)$ and $K(k)$ are the complete elliptical integrals of the first and second kind, respectively, and $v$ is Poisson's ratio. We estimated the $\Delta \sigma$ value of each foreshock so that $\mu A \bar{D}$, where $A=\pi a b$ and $\bar{D}$ is the average of $D$, is consistent with the seismic moment of each foreshock shown in Table 1. Figure 4b shows the slip distributions of the foreshocks obtained from Eq. (2).

\section{Appendix 2: Estimation of the dynamic coefficient of friction}

To estimate the stress drop of the main shock, we consider a half of an elliptical crack with a constant stress drop. The axes of the ellipse with an aspect ratio of $a / b$ correspond to the $x$ - and $y$-axes, respectively, and the slip direction is parallel to the $x$-axis. We set $a$ and $b$ to be the average length and width of those of the Hinagu and Futagawa fault planes estimated in "Estimation of fault 
planes" section, considering mirror images to include the free surface effect.

Madariaga (1977) evaluated the constant stress drop $\Delta \sigma$ in terms of the average slip, $\bar{D}$ :

$$
\Delta \sigma=\frac{\mu}{C_{2}} \frac{\bar{D}}{W}
$$

where $W$ is the minimum axis of the ellipse and $C_{2}$ is

$$
\begin{array}{ll}
C_{2}=4 /\left[3 E(k)+\frac{K(k)-(b / a)^{2} E(k)}{k^{2}}\right] ; & a>b, k=\sqrt{1-(b / a)^{2}} \\
=4 /\left[3 E(k)+\left(\frac{a}{b}\right)^{2} \frac{K(k)-E(k)}{k^{2}}\right] ; & b>a, k=\sqrt{1-(a / b)^{2}} .
\end{array}
$$

We assumed $\Delta \sigma$ is $\sum\left(\Delta \sigma_{i} A_{i}\right) / \sum A_{i}(i=\mathrm{H}, \mathrm{F})$, where $\Delta \sigma_{i}$ is $\tau^{\mathrm{r}}-\mu_{\mathrm{d}} \sigma_{\mathrm{n}}^{\mathrm{r}}$, and the subscripts $\mathrm{H}$ and $\mathrm{F}$ correspond to the Hinagu and Futagawa faults, respectively, ignoring the stress changes due to the foreshocks. Note that $\tau^{\mathrm{r}}$ and $\sigma_{\mathrm{n}}^{\mathrm{r}}$ are uniform on each of the Hinagu and Futagawa planar faults. We determined the $\mu_{\mathrm{d}}$ value, which is the same in the two faults, so that $\mu A \bar{D}$ is consistent with the observed seismic moment shown in Table 1, where $A=\pi a b / 2$. The obtained $\mu_{\mathrm{d}}$ values for cases $A-G$ are listed in Table 3.

\section{Publisher's Note}

Springer Nature remains neutral with regard to jurisdictional claims in published maps and institutional affiliations.

Received: 18 August 2017 Accepted: 13 October 2017

Published online: 01 November 2017

\section{References}

Fukuyama E et al (2000) NIED seismic moment tensor catalogue JanuaryDecember, 1999. Technical Note on National Research Institute Earth Science Disaster Prevention, vol 199, pp 1-56

Andrews DJ (1976a) Rupture propagation with finite stress in antiplane strain. J Geophys Res 81(20):3575-3582. doi:10.1029/JB081 i020p03575

Andrews DJ (1976b) Rupture velocity of plane strain shear cracks. J Geophys Res 81:5679-5687. doi:10.1029/JB081i032p05679

Andrews DJ (2004) Rupture models with dynamically determined breakdown displacement. Bull Seismol Soc Am 94(3):769-775. doi:10.1785/0120030142

Asano K, Iwata T (2016) Source rupture processes of the foreshock and mainshock in the 2016 Kumamoto earthquake sequence estimated from the kinematic waveform inversion of strong motion data. Earth Planets Space 68(1):147. doi:10.1186/s40623-016-0519-9

Eshelby JD (1957) The determination of the elastic field of an ellipsoidal inclusion, and related problems. Proc R Soc A Math Phys Eng Sci 241(1226):376-396. doi:10.1098/rspa.1957.0133

Fukuyama E, Suzuki W (2016) Near-fault deformation and DC $c^{\prime \prime}$ during the 2016 Mw7.1 Kumamoto earthquake. Earth Planets Space 68(1):194. doi:10.1186/s40623-016-0570-6

Hao J, Ji C, Yao Z (2017) Slip history of the 2016 Mw7.0 Kumamoto earthquake: intraplate rupture in complex tectonic environment. Geophys Res Lett 44:743-750. doi:10.1002/2016GL071543

Himematsu Y, Furuya M (2016) Fault source model for the 2016 Kumamoto earthquake sequence based on ALOS-2/PALSAR-2 pixel-offset data: evidence for dynamic slip partitioning (EPSP-D-16-00163). Earth Planets Space 68(1):169. doi:10.1186/s40623-016-0545-7
Hok S, Fukuyama E (2011) A new BIEM for rupture dynamics in half-space and its application to the 2008 Iwate-Miyagi Nairiku earthquake. Geophys J Int 184:301-324. doi:10.1111/j.1365-246X.2010.04835.x

Ida Y (1972) Cohesive force across the tip of a longitudinal-shear crack and Griffith's specific surface energy. J Geophys Res 77:3796-3805. doi:10.1029/JB077i020p03796

Kato A, Fukuda J, Nakagawa S, Obara K (2016a) Foreshock migration preceding the 2016 Mw7.0 Kumamoto earthquake, Japan. Geophys Res Lett. doi:10. 1002/2016GL070079

Kato A, Nakamura K, Hiyama Y (2016b) The 2016 Kumamoto earthquake sequence. Proc Jpn Acad 92:358-371. doi:10.2183/pjab.92.359

Kilb D, Gomberg J, Bodin P (2000) Triggering of earthquake aftershocks by dynamic stresses. Nature 408(6812):570-574. doi:10.1038/35046046

King GCP, Stein RS, Lin J (1994) Static stress changes and the triggering of earthquakes. Bull Seismol Soc Am 84(3):935-953

Kobayashi H, Koketsu K, Miyake H (2017) Rupture processes of the 2016 Kumamoto earthquake sequence: causes for extreme ground motions. Geophys Res Lett 44:1-9. doi:10.1002/2017GL073857

Kubo H, Suzuki W, Aoi S, Sekiguchi H (2016) Source rupture processes of the 2016 Kumamoto, Japan, earthquakes estimated from strongmotion waveforms. Earth Planets Space 68(1):161. doi:10.1186/ s40623-016-0536-8

Lin A, Satsukawa T, Wang M, Asl ZM, Fueta R, Nakajima F (2016) Coseismic rupturing stopped by Aso volcano during the 2016 Mw7.1 Kumamoto earthquake, Japan. Science 354(6314):869-874. doi:10.1126/science. aah4629

Madariaga R (1977) Implications of stress-drop models of earthquakes for the inversion of stress drop from seismic observations. Pure Appl Geophys 115(1-2):301-316. doi:10.1007/BF01637111

Okada Y (1992) Internal deformation due to shear and tensile faults in a halfspace. Bull Seismol Soc Am 82(2):1018-1040

Research Group for Active Faults of Japan (RGAFJ) (1991) Active faults in Japan. University Tokyo Press, Tokyo

Saiga A, Matsumoto S, Uehira K, Matsushima T, Shimizu H (2010) Velocity structure in the crust beneath the Kyushu area. Earth Planets Space 62(5):449-462. doi:10.5047/eps.2010.02.003

Shirahama Y et al (2016) Characteristics of the surface ruptures associated with the 2016 Kumamoto earthquake sequence, central Kyushu, Japan. Earth Planets Space 68(1):191. doi:10.1186/s40623-016-0559-1

Sibson RH (1992) Implications of fault-valve behaviour for rupture nucleation and recurrence. Tectonophysics 211(1-4):283-293. doi:10.1016/0040-1951(92)90065-E

Stein RS, Barka AA, Dieterich JH (1997) Earthquake stress triggering. Geophys J Int 128:594-604

Tada T, Madariaga R (2001) Dynamic modelling of the flat 2-D crack by a semi-analytic BIEM scheme. Int J Numer Methods Eng 50(1):227-251. doi:10.1002/1097-0207(20010110)50:1<227:AID-NME166>3.0.CO;2-5

Toda S, Stein RS, Beroza GC, Marsan D (2012) Aftershocks halted by static stress shadows. Nat Geosci 5(6):410-413. doi:10.1038/ngeo1465

Uchide T, Horikawa H, Nakai M, Matsushita R, Shigematsu N, Ando R, Imanishi K (2016) The 2016 Kumamoto-Oita earthquake sequence: aftershock seismicity gap and dynamic triggering in volcanic areas. Earth Planets Space 68(1):180. doi:10.1186/s40623-016-0556-4

Utsu T (2001) The seismology, 3rd edn. Kyoritsu, Tokyo, p 138

Waldhauser F, Ellsworth WL (2000) A double-difference earthquake location algorithm: method and application to the Northern Hayward Fault, California. Bull Seismol Soc Am 90(6):1353-1368. doi:10.1785/0120000006

Wessel P, Smith WHF (1998) New, improved version of Generic Mapping Tools released. Eos. Trans Am Geophys Union 79:579. doi:10.1029/98EO00426

Yagi Y, Okuwaki R, Enescu B, Kasahara A, Miyakawa A, Otsubo M (2016) Rupture process of the 2016 Kumamoto earthquake in relation to the thermal structure around Aso volcano. Earth Planets Space. doi:10.1186/ s40623-016-0492-3

Yamanaka H, Chimoto K, Miyake H, Tsuno S, Yamada N (2016) Observation of earthquake ground motion due to aftershocks of the 2016 Kumamoto earthquake in damaged areas. Earth Planets Space 68(1):197. doi:10.1186/ s40623-016-0574-2

Yoshida K, Hasegawa A, Saito T, Asano Y, Tanaka S, Sawazaki K, Urata Y, Fukuyama E (2016) Stress rotations due to the M6.5 foreshck and M7.3 mainshock in the 2016 Kumamoto, SW Japan, earthquake sequence. Geophys Res Lett. doi:10.1002/2016GL070581 